San Jose State University

SJSU ScholarWorks

Master's Theses

Master's Theses and Graduate Research

1993

\title{
Process control and vibration testing of fine pitch surface mount assemblies
}

Paul H. C Lo

San Jose State University

Follow this and additional works at: https://scholarworks.sjsu.edu/etd_theses

\section{Recommended Citation}

Lo, Paul H. C, "Process control and vibration testing of fine pitch surface mount assemblies" (1993). Master's Theses. 696.

DOI: https://doi.org/10.31979/etd.q8fa-fc37

https://scholarworks.sjsu.edu/etd_theses/696

This Thesis is brought to you for free and open access by the Master's Theses and Graduate Research at SJSU ScholarWorks. It has been accepted for inclusion in Master's Theses by an authorized administrator of SJSU ScholarWorks. For more information, please contact scholarworks@sjsu.edu. 


\section{INFORMATION TO USERS}

This manuscript has been reproduced from the microfilm master. UMI films the text directly from the original or copy submitted. Thus, some thesis and dissertation copies are in typewriter face, while others may be from any type of computer printer.

The quality of this reproduction is dependent upon the quality of the copy submitted. Broken or indistinct print, colored or poor quality illustrations and photographs, print bleedthrough, substandard margins, and improper alignment can adversely atfect reproduction.

In the unlikely event that the author did not send UMI a complete manuscript and there are missing pages, these will be noted. Also, if unauthorized copyright material had to be removed, a note will indicate the deletion.

Oversize materials (e.g., maps, drawings, charts) are reproduced by sectioning the original, beginning at the upper left-hand corner and continuing from left to right in equal sections with small overlaps. Each original is also photographed in one exposure and is included in reduced form at the back of the book.

Photographs included in the original manuscript have been reproduced xerographically in this copy. Higher quality $6 "$ " 9 " black and white photographic prints are available for any photographs or illustrations appearing in this copy for an additional charge. Contact UMI directly to order.

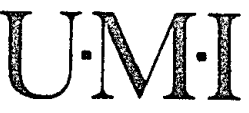

University Microfilms International

A Bell \& Howell Information Company 

Order Number 1956479

Process control and vibration testing of fine pitch surface mount assemblies

\author{
Lo, Paul H. C., M.S. \\ San Jose State University, 1993
}

Copyright (C)1993 by Lo, Paul H. C. All rights reserved.

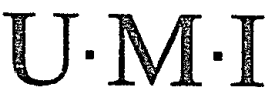

300 N. Zeeb Rd.

Ann Arbor, MI 48106 

PROCESS CONTROL AND VIBRATION TESTING OF FINE PITCH SURFACE MOUNT ASSEMBLIES

\author{
A Thesis \\ Presented to \\ The Faculty of the Department of Materials Engineering \\ San Jose State University
}

\author{
In Partial Fulfillment \\ of the Requirements for the Degree \\ Master of Science
}

by

Paul H. C. Lo

December, 1993 
(C) 1993

Paul H. C. Lo

ALL RIGHTS RESERVED 
APPROVED FOR THE DEPARTMENT

OF MATERIALS ENGINEERING

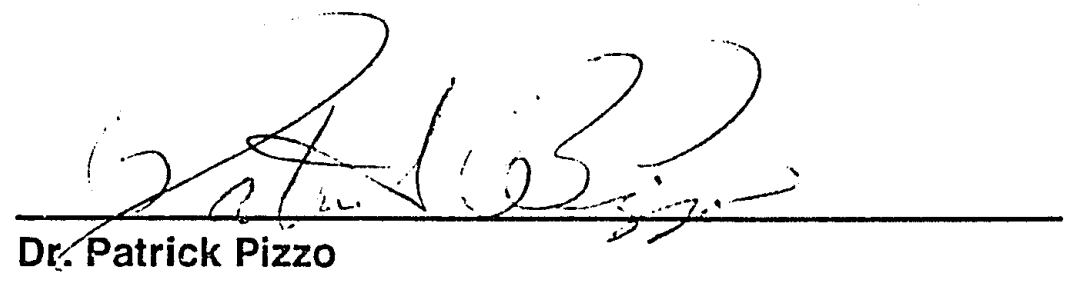

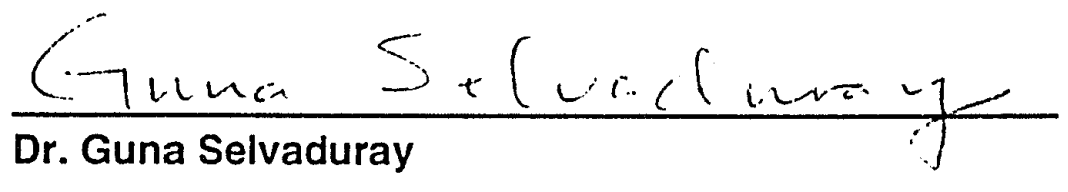

$$
\text { Sut wasters }
$$

Dr. Burt Masters

APPROVED FOR THE UNIVERSITY

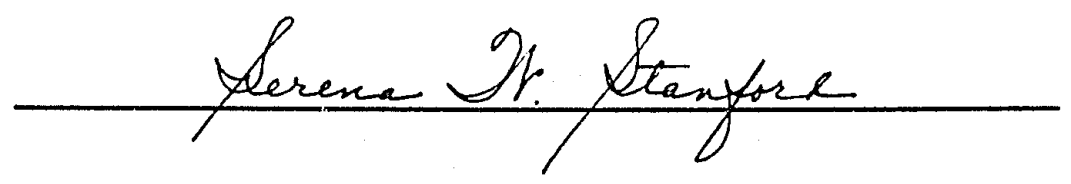




\title{
A.BSTRACT \\ PROCESS CONTROL AND VIBRATION TESTING \\ OF FINE PITCH SURFACE MOUNT ASSEMBLIES
}

\author{
by Paul H. C. Lo
}

Fine pitch infrared reflowed assemblies were investigated for process effects and fatigue characteristics of the gull-wing type solder joints. The assemblies were subjected to out-of-plane vibration testing and the method was investigated for its potential as a process verification tool. The solder joint crack mechanism was elucidated through methods of fractography.

High cycle, low acceleration vibration conditions were required to induce cracks in the solder joints. High acceleration vibrations resulted in lead failure at the lead shoulder rather than at the joint. It was found that cracks in the solder joints initiated in the heel and propagated along the interface between the intermetallic layer and the solder fillet. Thus, fatigue crack propagation was dependent on the presence of intermetallic at the joint and not on the volume of intermetallic present. Vibration testing was determined to be impractical as a process verification tool. 


\section{ACKNOWLEDGMENTS}

The author wishes to acknowledge the following individuals involved in this project:

At San Jose State University:

My advisor and reading committee members of the Materials Engineering Department, Professors Patrick Pizzo, Guna Selvaduray, and Burt Masters; Professor Fred Barez and Mr. Anton Rahardja, Professor and former graduate student, respectively, of the Mechanical Engineering Department; Professor Ping Hsu of the Electrical Engineering Department; and Mr. Glenn Wong, former Aerospace Engineering student.

In Silicon Valley:

Mr. Richard Groover and Mr. Gregg Bardel of VLSI Technology, Inc; Mr. Peiman Amoukteh, Dr. Munir Haq and Mr. Reggie Mannequil, formerly of Solectron Corporation; and Mr. Ted Lancaster of Hewlett-Packard. 
Table of Contents

1. INTRODUCTION.....................................................................................1

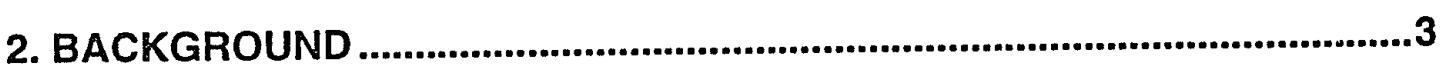

2.1 Surface Mount Technology ....................................................3

2.1.1 Benefits of SMT ............................................... 3

2.1.2 General Description of the Surface Mount Process ......3

2.1.3 Infrared (IR) Reflow ...........................................4

2.1.4 IR Reflow Profile ................................................ 5

2.1.5 The Reflow Process .............................................6

2.2 Surface Mount Lead Types ...................................................8

2.3 Soldering Phenomena ........................................................

2.3.1 Wetting of Surfaces ............................................ 9

2.3.2 The Formation of Intermetallics and the Presence of Other Compounds at the Joint ................................ 11

2.4 Solder Joint Materials ......................................................... 12

2.4.1 Solder Paste System ............................................ 12

2.4.2 Lead Materials....................................................... 13

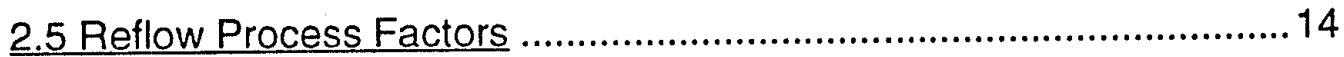

2.5.1 Time-Temperature Effects ..................................... 14

2.5.2 Noncoplanarity of the Package Leads........................ 15 
2.6 Joint Quality Evaluation ................................................................17

2.6.1 X-ray Laminography .................................................. 18

3. MECHANICAL INTEGRITY OF SOLDER JOINTS ......................................21

3.1 Process Parameters and Mechanical Properties .............................21

3.2 Mechanical Reliability Under Cyclic Loading ..................................22

4. RESEARCH HYPOTHESIS .......................................................................24

5. EXPERIMENTAL METHODOLOGY .........................................................25

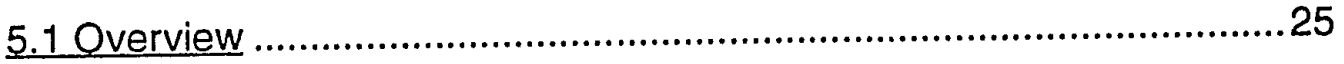

5.2 Preparation and Vibration Testing of the Assemblies .......................26

5.2.1 Type A.1 and A.2 Assemblies ...................................26

5.2.2 The Type B Assemblies ................................................32

5.2.3 Type $C$ and $D$ Assemblies .........................................33

5.3 Destructive Examination of Failed Assemblies ................................35

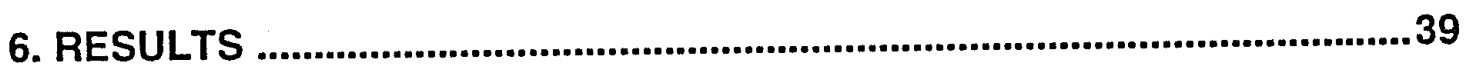

6.1 The Effects of Changes in the Reflow Time-temperature Profile ......39

6.1.1 Process Temperature Variations for the Type A.1 and A.2 Assemblies .......................................................39

6.1.2 X-ray Laminography of the A.1 and A.2 Assemblies ..... 42

6.1.3 Intermetallic Formation of the A.1, A.2, C, and D Assemblies

6.1.4 Solder Joint Defects in the C and D Assemblies............46

6.2 Fatigue Failure of Package Leads....................................................49

6.3 Examination of the Solder Joint Fracture and Determination of Fracture Mechanism. .53 


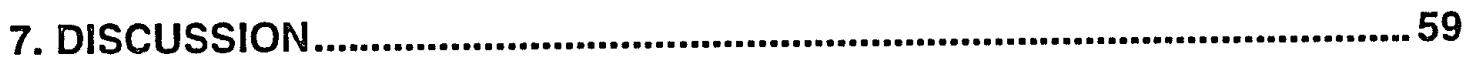

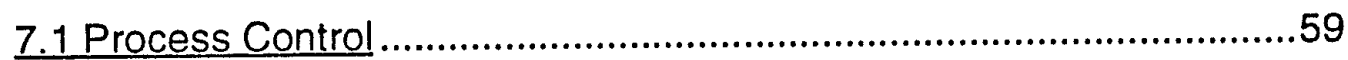

7.1.1 Intermetallic Formation.................................................59

7.1.2 Void Formation .............................................................60

7.2 X-ray Laminography as an Analytical Tool........................................62

7.3 Vibration Testing of Fine Pitch Solder Joints ...................................62

7.3.1 Solder Joint Cracking ......................................................62

7.3.2 Assembly Failure ...........................................................64

7.4 Out-of-Plane Vibration Testing and Process Evaluation ....................66

7.4.1 Vibration Testing as a Measure of Solder Joint Integrity ............................................................................66

7.4.2 Implementation of Vibration Testing ..............................67

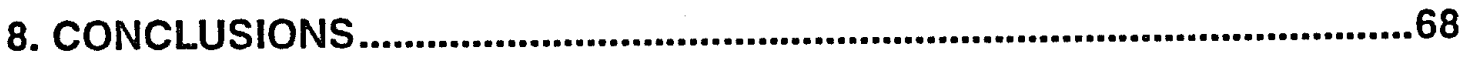

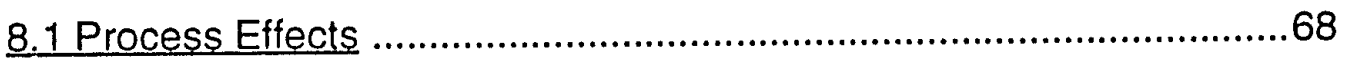

8.1.1 Process Control in a Commercial Assembly Line .........68

8.1.2 Thermal Differential Across an Assembly during Reflow ............................................................................68

8.2 Out-of-plane Vibration Testing ........................................................69

8.2.1 Crack Mechanism at a Gull-wing Solder Joint ...............69

8.2.2 The Character of Lead Failure ..........................................69

8.2.3 Vibration Testing as a Process Verification Tool ............69

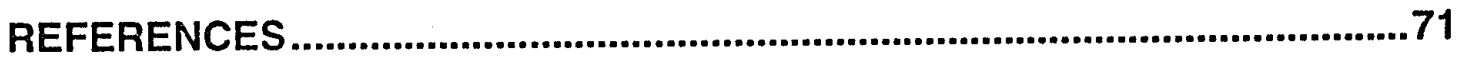

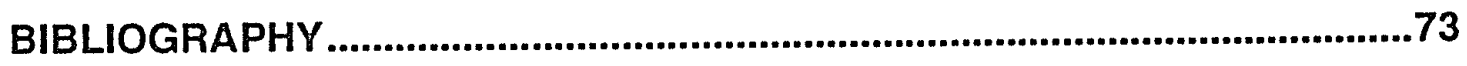




\section{List of Tables}

1. The Characteristics of Three Surface Mount Lead Configurations 8

2. Some Mechanical and Thermal Properties of Various Joint Materials. 13

3. Electrical and Thermal Properties of Three Lead Materials 14

4. Various Test Conditions for Assemblies Investigated 25

5. The Altered Parameters of the A.2 Assemblies 28

6. Nominal Temperature Set Points and Conveyor Speed for the A -Series Assemblies

7. Void Density in the Type C Assemblies

8. Void Density in the Type D Assemblies

9. Elongation for Copper and Pb-Sn Eutectic Solder .65 


\section{List of Figures}

1. A typical IR five zone time-temperature profile. ..................................6

2. The five reflow stages with respect to time and temperature.....................7

3. An illustration of the relationships between interfacial tensions and the contact angle of a liquid droplet on a solid substrate.

4. Schematic layout of the X-ray laminography machine ............................. 19

5. An illustration of the $X$-ray laminography focusing principle.......................20

6. A distribution of reliability under vibration loading of SMT solder joints. .......23

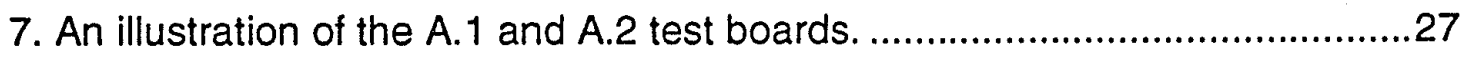

8. A diagram of the vibration testing system. ......................................... 30

9. An illustration showing the attachment point for the vibration testing of the A. 1 and A.2 assemblies.

10. Schematic of the B assemblies.

11. The layout of the $C$ and $D$ assemblies.

12. A micrograph of a typical mounted assembly that was prepared by a lead profile polish

13. Photomicrograph of a transverse section of a 208 lead $0.50 \mathrm{~mm}$ pitch MQFP at $50 \times$ magnification.

14. The time-temperature profiles of the A.1 (typical condition) assemblies.

15. The time-temperature profiles of the A.2 (extreme condition) assemblies. 
16. The superimposed location 3 (closest to center) time-temperature profiles of the A.1 and A.2 assemblies.

17. A solder joint processed under the A.1 condition......................................... 44

18. A micrograph of a solder joint in an A.2 assembly.......................................45

19. An overview of a typical solder joint in an A.1 assembly showing the uniformity of the intermetallic layer. ..............................................................46

20. A gull-wing lead showing the presence of a void extending from the soldering land to the lead.

21. A frontal polished $C$ assembly with a void in the fillet in a region adjacent to the edge of the lead.

22. A profile view of an Alloy 42 lead broken at the shoulder.

23. A top view of the fractured shoulders of a copper alloy 208 lead MQFP.

24. A close-up view of a copper lead at the fracture origin................................52

25. Crack initiation at the fillet heel. ...............................................................54

26. A cross sectional view of a polished partially cracked lead. .........................55

27. Cross section of a lifted lead. ...................................................................56

28. SEM micrograph of the fracture surface showing the presence of intermetallics along the lead/ solder interface.

29. A scanning electron micrograph showing a plateau at the heel of the fillet where cracks initiate. 


\section{INTRODUCTION}

Of much technological interest in the electronics industry is the reduction of device size in order to manufacture products of increasing utility with minimum bulk. This goal is achieved by a combination of technologies. Chip fabrication technology and therefore device functional density has advanced at an exponential rate in the past two decades. In turn, these trends place greater requirements on the next level of the electronics manufacturing process, a secure and functional place of residence, or a package, for the chip. In the past, with lesser levels of circuit integration, microelectronics packaging has generally not been a great hindrance to chip performance. Increased functional density of the chip translates to increased functional density of the interconnects. As a result, a typical modern electronic integrated circuit will contain many leads of fine dimensions.

Providing channels of communication between components is accomplished through use of a printed circuit board (PCB) and the mature craft and contemporary science of soldering. The fundamental purposes of soldering are to provide a stable medium for electron flow between components and adhesion of the component to the PCB. A method called surface mount technology (SMT), with a name that reflects its character, is a modern technique of joining components to the printed circuit board where packages are mounted directly on the board surface in contrast to the prior through-hole technique. Surface mounted solder joints are distinct from through-hole joints in the fact that they function not only as an electrical connection between the component and circuit board, but as the sole mechanical connection as well. Therefore, failure of 
surface mounted joints is of far greater consequence and attention to the soldering process is far more critical when compared to the through-hole method.

The objective of this investigation was to examine several factors in the SMT soldering process and determine their influence on solder joint integrity. Solder joint integrity, in this study, refers to the mechanical quality of the joint after the reflow process. Factors affecting the quality of the joint include its geometry, which is a function of the wetting characteristics of the liquefied solder and the dimensions of the lead, the degree of intermetallic formation, a factor that influences wetting, and the type of solder microstructure formed, a characteristic which determines mechanical properties. There is no singular generally accepted means to assess solder joint integrity. The proposed method in this study was to subject the joints to sinusoidal mechanical loading to investigate whether the statistical distribution of time-to-failure data define a quality joint and a deviation from quality. This type of testing is proposed as a potential process verification tool.

Solder joint integrity has a relationship to solder joint durability. Durability is defined as integrity over a period of time in a definite environment. A difficulty exists in establishing the relationship between initial integrity and long-term durability. There exists no reliable standard tests for this objective.

The focus of this study is solder joint mechanical integrity. It is an investigation of surface mount process factors that determine integrity and a potential method of discerning integrity. 


\section{BACKGROUND}

\subsection{Surface Mount Technology}

\subsubsection{Benefits of SMT}

Surface mounted components (SMC) are relatively small in size, low in weight and may be mounted on both sides of a circuit board.(1) These factors result in a significant reduction of real estate compared to pin-through-hole components. The component size reduction offered by SMC design is directly related to a reduction of lead pitch. A pitch of $1.27 \mathrm{~mm}$ or less is usually referred to as fine pitch. For comparison, a through-hole dual-inline-package (DIP) has a pitch of $2.54 \mathrm{~mm}$. Since not all components in a typical assembly are available in the surface mounted configuration and a mixture of through-hole and surface mounted components may be required, the total size reduction is also dependent on the relative amounts of the two respective types.

\subsubsection{General Description of the Surface Mount Process}

The surface mount process for a general single-sided surface mount only assembly is as follows. The first step is to dispense the solder paste onto the bonding area, or lands, on the printed circuit board (PCB). This is usually accomplished by syringe application or screen printing. The average spot diameter of the dispensed paste can be controlled to about $\pm 0.05 \mathrm{~mm}$ with standard equipment.(2) Next, the electronic components are placed by machine onto the paste. Though the consistency of the paste holds the components in place, careful handling of the assembly before soldering must be adhered to in order to avoid misalignment . 
The next stage is the reflow of the solder paste. The main function of reflow is to melt the solder material, wet the surfaces to be joined, and re-solidify the solder to form a metallurgical bond. Reflow is executed by several heating methods: infrared, vapor phase, convection, conduction belt, and laser soldering. Due to its increasing presence in industrial assembly operations, the infrared method was utilized this study.

\subsubsection{Infrared (IR) Reflow}

The infrared (IR) region of the electromagnetic spectrum is the portion which contains wavelengths ranging from 0.72 to $1000 \mu \mathrm{m}$. The spectral distribution of a body emitting radiation can be described by $R_{T}(v)$, called the spectral radiancy, where $v$ is the frequency of the emitted radiation and $R_{T}(v)$ is defined as the energy emitted per unit time in the frequency interval $v+d v$ at an absolute temperature $T$. The radiancy $R_{T}$ is given by the relationship

$$
R_{T}=\int_{0}^{\infty} R_{T}(v) d v \text { Eq. (1) }
$$

An empirical form of this relationship called Stefan's Law is expressed as

$$
R_{T}=\sigma T^{4} \quad \text { Eq. (2) }
$$

where $\sigma$ is the Stephan-Boltzmann constant with a value of $5.67 \times 10^{-8} \mathrm{~W} / \mathrm{m}^{2}$. $\mathrm{K}^{4}$. Equation 2 indicates that spectral radiance is dependent upon the 4th power of emitter temperature, and thus board temperature, from an IR reflow system is difficult to control.

The position of the radiation distribution peak is given by the Wien displacement Law:

$$
v_{\max } \alpha T . \quad \text { Eq. (3) }
$$

Equation 3 shows that the maximum frequency of the emitter is linearly proportional to temperature. Common reflow equipment emitter materials are 
tungsten, which operates from 0.7 to $3 \mu \mathrm{m}$, and resistive heating elements for the longer wavelengths from 3 to $8 \mu \mathrm{m}$. The radiation is absorbed by the circuit board assembly materials and this energy is used to melt the solder. Peak IR reflow temperatures encountered by the assembly materials are typically $215^{\circ} \mathrm{C}$ to 260 ${ }^{\circ} \mathrm{C}$. This is approximately $25^{\circ} \mathrm{C}$ to $40^{\circ} \mathrm{C}$ greater than $\mathrm{Pb}-\mathrm{Sn}$ eutectic solder's liquidus temperature.

\subsubsection{IR Reflow Profile}

It has been noted ${ }^{(3)}$ that the infrared reflow environment is not an equilibrium method of heating. The degree of IR energy absorbed is a function of spectral reflectance and the volume of material on the surface mount assembly. For a large circuit board assembly, a temperature difference of $20^{\circ} \mathrm{C}$ from the edge of the board (the low mass low temperature area) to the center of the board (the high mass high temperature area) may result. The highly absorbing species at the IR wavelengths are the organic matirials in the circuit board and the package body, if constructed of plastic. The metallic materials in the assembly reflect, or absorb very little of, the radiation and primarily serve to conduct heat. An individual assembly has a variety of electronic components and board configurations and a unique time temperature profile. A typical time-temperature profile is shown in Figure 1 to illustrate the temperature differences with respect to time into the reflow cycle. 


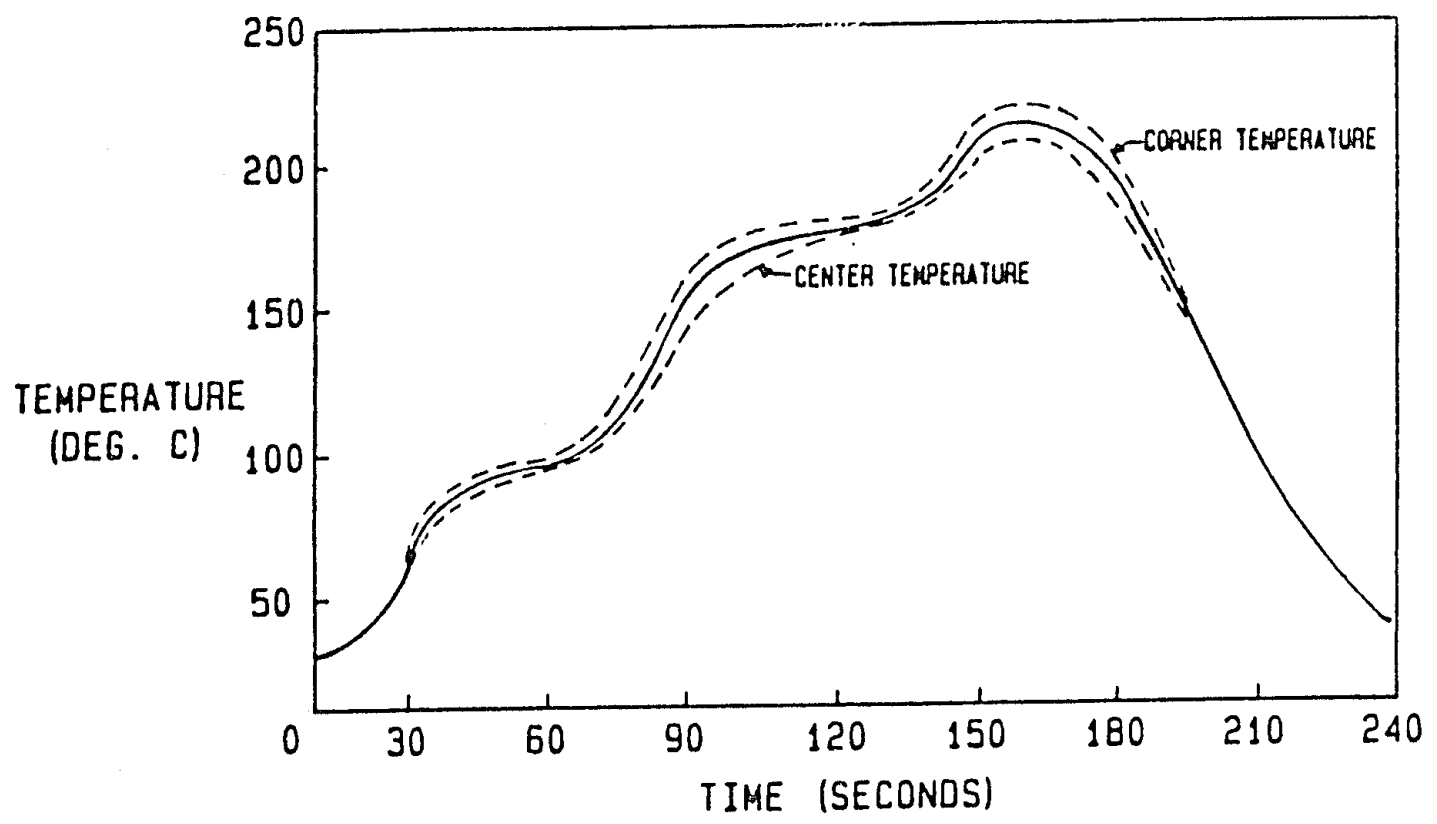

Figure1. A typical IR five zone time-temperature profile.(Hutchins 1987)

Since the actual temperature at a particular solder joint is dependent upon the mass of the local organic materials, a joint at the ends of a given line of leads on a package may experience a lower temperature than one positioned on the center of the line. Thus, the characteristics of the formed fillet may vary across the line of leads. A function of the lead in the IR reflow process is to conduct heat to the joint. Therefore, successful soldering is dependent upon the heat conductivity of the lead material. This property requires consideration in the selection of a particular time-temperature profile.

\subsubsection{The Reflow Process}

The general reflow events ${ }^{(4)}$ for $\mathrm{Pb}$-Sn eutectic solders can be categorized into five phases with respect to the time-temperature profile, as illustrated in 
Figure 2. The first phase is evaporation of the solvent within the solder paste as the temperature approaches $100^{\circ} \mathrm{C}$. A detailed description of the composition and the function of a solder paste system is provided in a following section. The second phase is the reduction of metal oxides by the solder flux on the soldering surfaces at temperatures up to $150^{\circ} \mathrm{C}$. The third phase is where melting of the solder begins. At this stage, the fluxed surfaces become wetted. Above the liquidus temperature, the melted solder forms a shape determined by the balance of the surface tensions of the material surfaces and by the geometries involved. During final cool down, the final phase, a solid solder fillet forms and adhesion between surfaces results.

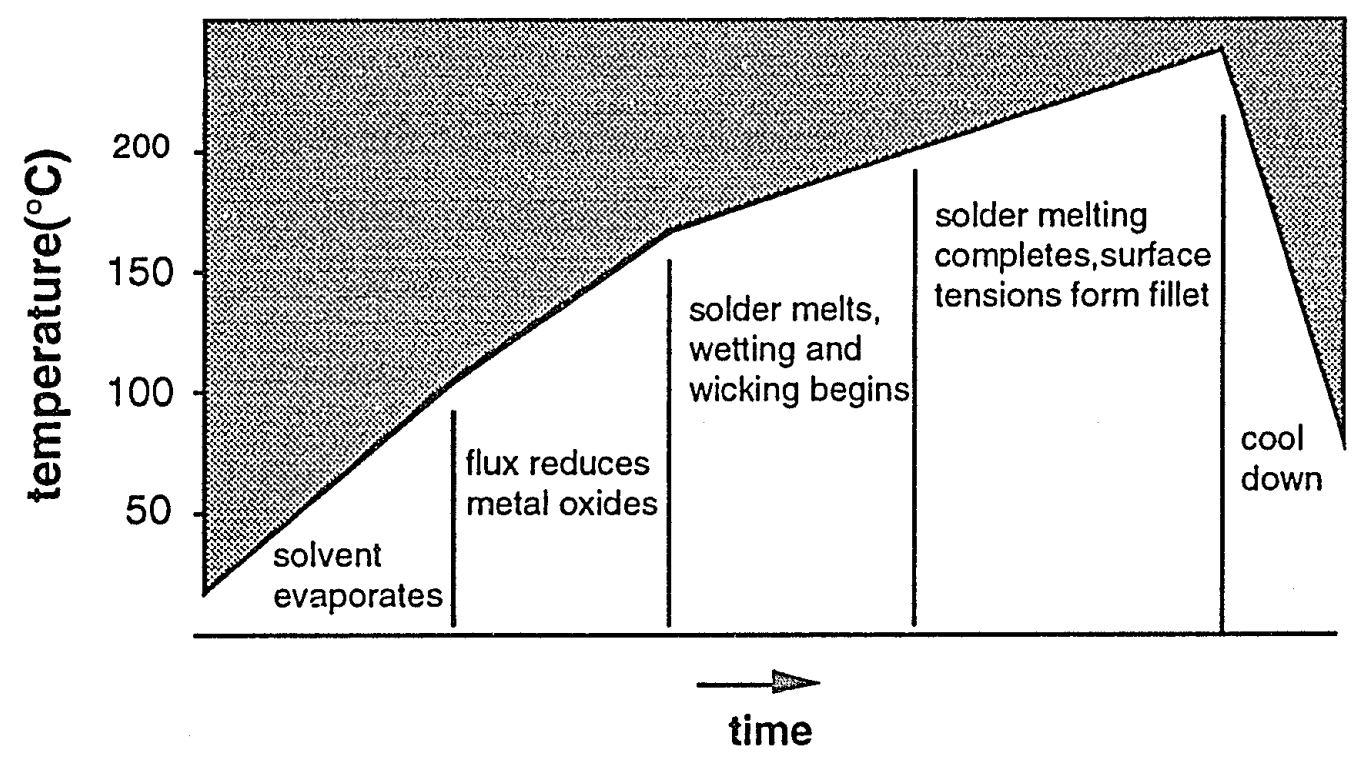

Figure 2. The five reflow stages with respect to time and temperature.

After reflow, the assembly is then cleaned of residuals of the solder paste flux whose presence has a corrosive effect on the assembly materials. 


\subsection{Surface Mount Lead Types}

In general, the larger the lead count of a given package, the finer the pitch of the leads. This results in smaller bond areas and increased fragility of these interconnection points. Lead configurations used in surface mount are the gullwing lead, the $J$-lead, and the butt-lead (l-lead). The type of lead plays a role in the mechanical integrity of the solder joint. A summary of the respective lead types and their characteristics is given in Table 1.

Table 1. The Characteristics of Three Surface Mount Lead Configurations

\begin{tabular}{|c|c|c|c|}
\hline ITEM & GULL.WING & J.LEAD & BUTT-LEAD \\
\hline $\begin{array}{l}\text { Compatibility with future } \\
\text { Multi-Pin Package Irend }\end{array}$ & (O) & & $\triangle$ \\
\hline Package Thickness & (0) & & $\Delta$ \\
\hline Lead Rigidity & $\Delta$ & (O) & \\
\hline $\begin{array}{l}\text { Compatibility With Multiple } \\
\text { Soldering idethods }\end{array}$ & (0) & & \\
\hline $\begin{array}{l}\text { Abittly To Self-Align During } \\
\text { Reflo.y }\end{array}$ & (a) & ( & $\triangle$ \\
\hline $\begin{array}{l}\text { Accessibility For Inspaction } \\
\text { After Soldering }\end{array}$ & & C & \\
\hline Eaje Oi Clearing & 0 & (O) & (O) \\
\hline Real Estate Effíiency & $\triangle$ & (O) & 0 \\
\hline
\end{tabular}

Source: Surface Mount Technology-Principles and Practice, Van Nostrand Reinhold, New York, (1989), p. 107. 
The main advantage of the gull-wing lead is its ability to provide a low profile outline. This is compatible with a trend toward thin, fine lead packages. (5) Its main liability is its susceptibility to damage during shipping and handling when compared to the sturdier J-lead. Also, inspection of the solder fillet on a gull-wing lead after reflow is more difficult since the larger end (the heel) of the fillet is toward the center of the package as opposed to the exterior of the package, as is the case, for the J-lead.

Of popular use in surface mounted components (and a typical example of a fine pitch SMC) is the metric quad flat pack (MQFP). (6) The main body material consists of epoxy molding compound. Distinguishing features of this package type are its specification adherence to the metric system, lead protrusion on all four sides of its rectangular or square body, and high lead count. For a given package body dimension of $28 \mathrm{~mm} \times 28 \mathrm{~mm}$, the lead count can vary from 108 with a $1 \mathrm{~mm}$ external pitch to 208 with a $0.5 \mathrm{~mm}$ external pitch.

\subsection{Soldering Phenomena}

\subsubsection{Wetting of Surfaces}

The degree and manner in which the solder wets a component lead is an important factor in determining the quality of the resultant solder joint. A fundamental description of the phenomenon of wetting can be described by the following model. Consider a liquid droplet on a solid surface in air, at equilibrium, as shown in Figure 3. The degree to which the liquid will spread around or "wet" the solid substrate is quantified by an angle $\theta$ defined by a tangent to the point at which the liquid contacts the surface, as shown in the figure. This is termed the contact angle. This angle is determined by the balance between the respective 
interfacial surface tensions of the liquid, solid, and vapor phases. An expression derived from force balance considerations known as Young's Equation describes the wetting extent or "ability":

$$
\gamma_{S V}=\gamma_{S L}+\gamma_{L V} \cos \theta \quad \text { Eq. (4) }
$$

or rearranged as

$$
\theta=\cos ^{-1}\left[\frac{\gamma_{S V}-\gamma_{S L}}{\gamma_{L V}}\right] \quad \text { Eq. (5) }
$$

where $\gamma$ is the interfacial surface tension and the subscripts $S V, S L$, and $L V$ refer to the respective surface tensions of the solid-vapor, solid-liquid, and the liquid-vapor interfaces.

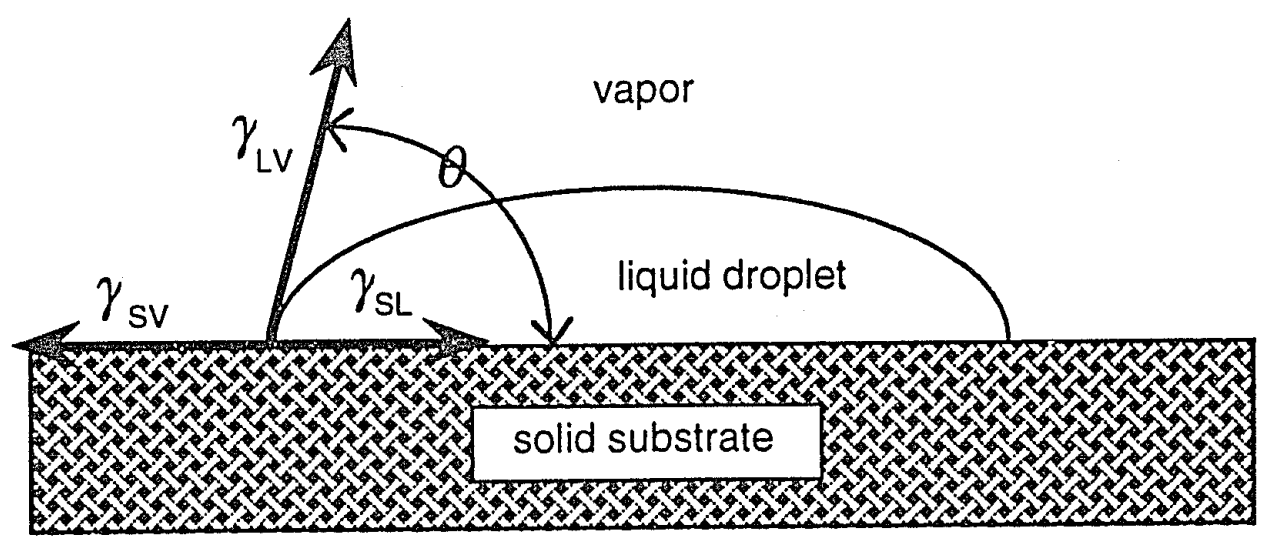

Figure 3. An illustration of the relationships between interfacial tensions and the contact angle of a liquid droplet on a solid substrate.

The standard definitions of wetting ability are non-wetting when $180^{\circ}>\theta>90^{\circ}$, partial-wetting when $\theta<90^{\circ}$ and total-wetting when $\theta=0^{\circ}$. 
The configuration of surface mounted solder leads has greater geometric variance than the model described above and thus more interacting forces are present but the basic principles are applicable. The solidified solder configuration is a function of the soldering system's interfacial surface tensions and their respective vectorial orientations during wetting.

\subsubsection{The Formation of Intermetallics and the Presence of Other Compounds at the Joint}

Copper is a common lead material. The intermetallic compounds found in the Cu-Pb-Sn system are $\mathrm{Cu}_{6} \mathrm{Sn}_{5}$ and $\mathrm{Cu}_{3} \mathrm{Sn}$. Intermetallic formation is the primary mechanism of adhesion at the soldering surfaces in the $\mathrm{Cu}-\mathrm{Pb}-\mathrm{Sn}$ system and is therefore critical to the mechanical integrity of a joint.(7) Nonetheless, excessive time dependent growth of intermetallics can cause embrittlement and reduced ductility at the joint. Solder embrittlement may lead to mechanical failure due to reduction in the solder connection's ability to withstand shock and vibration loads. The decreased ductility reduces the joint's ability to tolerate alternating and sustained stresses such as those encountered as a result of thermal coefficient mismatch between the printed circuit board, the lead, and the solder and the presence of stress raisers.

In addition, the content of fluxes in solder pastes may create inclusions or voids in the soldered material, resulting in decreased adhesion surface area. 


\subsection{Solder Joint Materials}

\subsubsection{Solder Paste System}

The most commonly used solder composition is that of the Pb-Sn eutectic. It has a liquidus temperature of $183^{\circ} \mathrm{C}$. In SMT, the solder is applied in the form of a paste system consisting of metallurgical powders and accompanying flux. The flux can occupy up to $50 \%$ by volume of the entire paste and its composition is function specific.

The components of a generic flux are rosin/resin, solvent, activator, thickeners/ rheological agents, and other additives.(8) Formulations may also contain multiple permutations of resins, activators, and thickeners.

Resins contribute to the wetting ability by reducing the metal oxides on the surfaces of the lead, metallic powder, and substrate. They may also give the paste characteristics such as tack, necessary for paste contact to the lands during handling operations prior to reflow. Solvents function in this paste system to dissolve the resins and activators.

Activators are substances that aid the resin in cleaning the surface of the metal powders and soldering surfaces of oxides in order to subsequently attain superior wetting. The chemical composition of activators vary substantially including inorganic acids and salts, amine hydrohalides, and organic acids and bases. An operating term "flux activity" is somewhat loosely defined as a gauge for wetting ability and post reflow corrosiveness of the flux. A common classification for rosin containing fluxes is defined in the specification QQ-S571E, which is the charge of the U.S. Army Electronics Research and Development Command. The three general classifications for rosin based fluxes are, in increasing level of activity, rosin or resin-only (R), rosin-mildly-activated 
(RMA), and rosin-activated (RA). Other flux designations include organic acid $(\mathrm{OA})$, super-rosin-activated (SRA), and synthetic-activated (SA).

Thickeners, viscosity modifiers, or rheological control agents function to thicken the flux therefore providing paste-like consistency. These substances control the flow characteristics of the powder in order to result in consistent application with regard to size and geometry of the paste in the dispensing process and immobility in subsequent handling procedures. In addition, these substances provide an even dispersion of the metal particles within the body of the paste.

\subsubsection{Lead Materials}

With regard to the reflow process, material properties of interest for a lead are mechanical strength and thermal conductivity. The most common lead materials are a group of copper based alloys $\left({ }^{(9)}\right.$ and Alloy 42 (composition: $42 \%$ nickel $58 \%$ iron). Alloy 42 is a material which possesses superior mechanical properties to copper. The yield strength of Alloy 42, as shown in Table 2, is greater than those of two typical lead copper alloys and would aid in avoiding lead damage prior to reflow.

Table 2. Some Mechanical and Thermal Properties of Various Joint Materials

\begin{tabular}{llll}
\hline Material & Designation & $\begin{array}{l}\text { Yield Strength } \\
\text { (MPa) }\end{array}$ & $\begin{array}{l}\text { Coeff. of Therm. EX. } \\
\text { at } 20^{\circ} \mathrm{C} \text { to } 300^{\circ} \mathrm{C} \\
\left(10^{-6} / \mathrm{K}\right)\end{array}$ \\
\hline Cu-Fe alloy & C19400 & 480 & 17.4 \\
Cu-Sn alloy & C 50710 & 415 & 17.8 \\
Alloy 42 & ASTM F30 & 620 & $4.0-4.7$ \\
Pb-Sn eutectic & - & - & $21^{*}$ \\
\hline
\end{tabular}

Sources: Electronic Materials Handbook, Volume 1. Packaging, ASM International, Materials Park, Ohio, (1989), p.491.

"Microelectronics Packaging Handbook, Van Nostrand Reinhold, New York, (1989), p. 278. 
Alloy 42 has several disadvantages over the copper based alloys. As shown in Table 3, Alloy 42 has distinctively lower thermal conductivity than the copper alloys. The inferior thermal conductivity can lead to inadequate heat transfer to the soldering surfaces during the reflow process. In addition, a greater mismatch of the coefficients of thermal expansion between Alloy 42 and the $\mathrm{Pb}$ $\mathrm{Sn}$ eutectic than between the copper alloys and the $\mathrm{Pb}-\mathrm{Sn}$ eutectic, as can be seen from Table 2, can introduce greater thermal stresses in subsequent service of the assembly. As tabulated in Table 3, Alloy 42 also possesses higher electrical resistivity and this is a consideration in devices that transmit high currents.

Table 3. Electrical and Thermal Properties of Three Lead Materials

\begin{tabular}{llll}
\hline Material & Designation & $\begin{array}{l}\text { Elec. Resistivity } \\
(\mu \Omega-\mathrm{cm})\end{array}$ & $\begin{array}{l}\text { Therm. Conductivity } \\
(\mathrm{W} / \mathrm{m}-\mathrm{K})\end{array}$ \\
\hline Cu-Fe alloy & C19400 & 2.54 & 260 \\
Cu-Sn alloy & C50710 & 5.75 & 120 \\
Alloy 42 & ASTM F30 & 70 & 12 \\
\hline
\end{tabular}

Source: Electronic Materials Handbook, Volume 1. Packaging, ASM International, Materials Park, Ohio, (1989), p. 490.

\subsection{Reflow Process Factors}

\subsubsection{Time-Temperature Effects}

The time-temperature profile of the reflow process is an important factor in the formation of a high quality solder joint. The time at which the joint is held above the melting temperature of the solder needs to be sufficient to allow for wetting of the lead and the land by the molten solder. An extended duration will promote the formation of excessive intermetallics and may thereby reduce the 
mechanical integrity of the joint. The peak reflow temperature should be adequately high such that flux action and solder flow properly occur. An excessively high temperature may cause component and board damage or discoloration. The cooling rate of the solder joint determines the grain size of the solder.(10) Rapid cooling produces a finer grain structure and produces a joint with superior fatigue resistance.

A particular $I R$ reflow time-temperature profile is determined by oven settings of the conveyor belt speed and the panel temperatures. Cooling rate is usually controlled by a fan. Recommended values of profile variables(11) are, respectively, a minimum heating time of 20 seconds and a maximum time of 80 seconds, a peak temperature of between $220^{\circ} \mathrm{C}$ and $230^{\circ} \mathrm{C}$, and a cooling rate of $10^{\circ} \mathrm{C} /$ second.

\subsubsection{Noncoplanarity of the Package Leads}

Coplanarity is defined as the distance of a lead above or below a plane defined by the average distance of all component leads. This definition is difficult to implement on the manufacturing floor.(12) Noncoplanarity refers to the difference in distance between the seating plane, which is defined by the lowest sitting lead, and the highest sitting lead. A consequence of noncoplanarity is that a single "unacceptable" lead can skew the entire profile of the component and can cause substrate-lead standoff to varying degrees for many leads. The Joint Electronic Device Engineering Council (JEDEC) established a maximum acceptable noncoplanarity value of $0.1016 \mathrm{~mm}$ ( 4.0 mils) for surface mount components.

Noncoplanarity, in general, causes inconsistent fillet formation during reflow. In the worse case, it may cause complete wicking of the solder up a lead, 
thereby resulting in an open joint. Noncoplanarity is introduced by damage during shipping, handling, and placement operations. Leads near the corner of the package are the most susceptible to distortion in the case of the MQFP. Higher lead count packages exhibit greater incidence of noncoplanarity due to the higher statistical probability of a deformed lead in a given package.

\subsubsection{Solder Paste}

A problem associated with activators in a solder paste system is that their residual products have a corrosive effect on the electronic components and thus they need to be purged from the circuit board. Ease of cleaning is therefore a factor in solder paste selection. The post-reflow cleaning requirements generally increase with an increasing level of flux activity in the solder paste system. Therefore, the various pastes are also characterized by the post soldering cleaning method. Typical systems are classified as no-clean, aqueous clean, and solvent cleaned. The solvent has traditionally been a chlorofluorocarbon (CFC) agent.

In the last decade, CFCs have been implicated as the initiator of the depletion of stratospheric ozone.(13) The resulting increase in transmitted ultraviolet radiation into the atmosphere causes deleterious effects in biological and agricultural systems. The Montreal Protocol, a United Nations crafted international agreement, was signed in 1987. It calls for a $50 \%$ reduction in CFCs by 1998 based upon 1986 usage data. An amendment was added to this document in June of 1990 based upon a technology assessment. It now includes provisions for the total elimination of CFCs and other chlorinated solvents (such 
as carbon tetrachloride) by the end of the century. Methyl chloroform has a phaseout date of 2005.

Because of environmental issues, the current trend in electronics cleaning has been to avoid CFC use, and to evaluate and use alternative nonhalogenated solvents such as terpenes and aqueous saponifires. ${ }^{(14)}$ The no-clean option is preferred due to its intrinsic efficiencies in this respect. Organic acid (OA) type pastes are water soluble and cleaning can be accomplished by the aqueous cleaning method.

\subsection{Joint Quality Evaluation}

In general, the quality of an individual joint is evaluated by observation of the appearance of the fillet form in order to determine if proper wetting has occurred during reflow. Geometric parameters of merit are dependent upon lead configuration.

Visual inspection of the fillet is the most direct method but poses inherent problems. This method requires a degree of experience and subjectivity on the part of the inspector. Joints may also be in a position on the assembly which may not be accessible for inspection. Additionally, the small size of the joint area and high lead count of modern packages presents tedium to the procedure. Electrical continuity monitoring is an inspection option but it reveals only total breaks and is effective only when performed in conjunction with simultaneous shaking of the assembly. If a lead in a given component is in physical contact with the substrate (and therefore conducts electricity) but lacks proper mechanical adhesion, potential signal transmission failure and thus device failure may result. A continuity check would not be able to evaluate this situation. 
The criteria for a suitable evaluation method must be non-destructive and automated for high speed data acquisition and processing. The collected data need to be compared with a qualified model which predicts accurately joint quality.

\subsubsection{X-ray Laminography}

A method which meets the criteria above currently under evaluation for industrial use is $X$-ray laminography ${ }^{(15)}$, or scanned beam laminography. This method produces X-ray images of slices of a solder joint. The slicing feature of this technique allows for inspection of visually hindered areas of the circuit board. Figure 4 shows the hardware setup for the apparatus. A magnetic steerer produces a circular rotation of an electron beam in a microfocus $\mathrm{X}$-ray tube. A Xray detector plate is rotated in synchronization with that of the electron tube and the image is then transferred, via mirrors, to a video camera where it is coupled to high speed computers for processing and analysis. A XYZ table moves the circuit board in order to scan its entire volume. The acquired data is evaluated by software to determine the quality of fillet formation.

The operating principle of the slicing function of the apparatus is illustrated in Figure 5. As the beam/detector assembly is rotated, the projection of planar points $A$ and $B$ on the detector surface remain stationary. Point $C$, however, which is out of the plane of points $A$ and $B$, is distributed over a wide area and will have no distinct contrast over the rotation cycle. Consequently, points on the $A B$ plane yield a high contrast relative to points out of the plane. This plane can be referred to as the focal plane. The focal plane can be varied dependent upon application. A typical range of thickness of the focal plane of a commercial machine is about 0.25 to $0.5 \mathrm{~mm}$. 


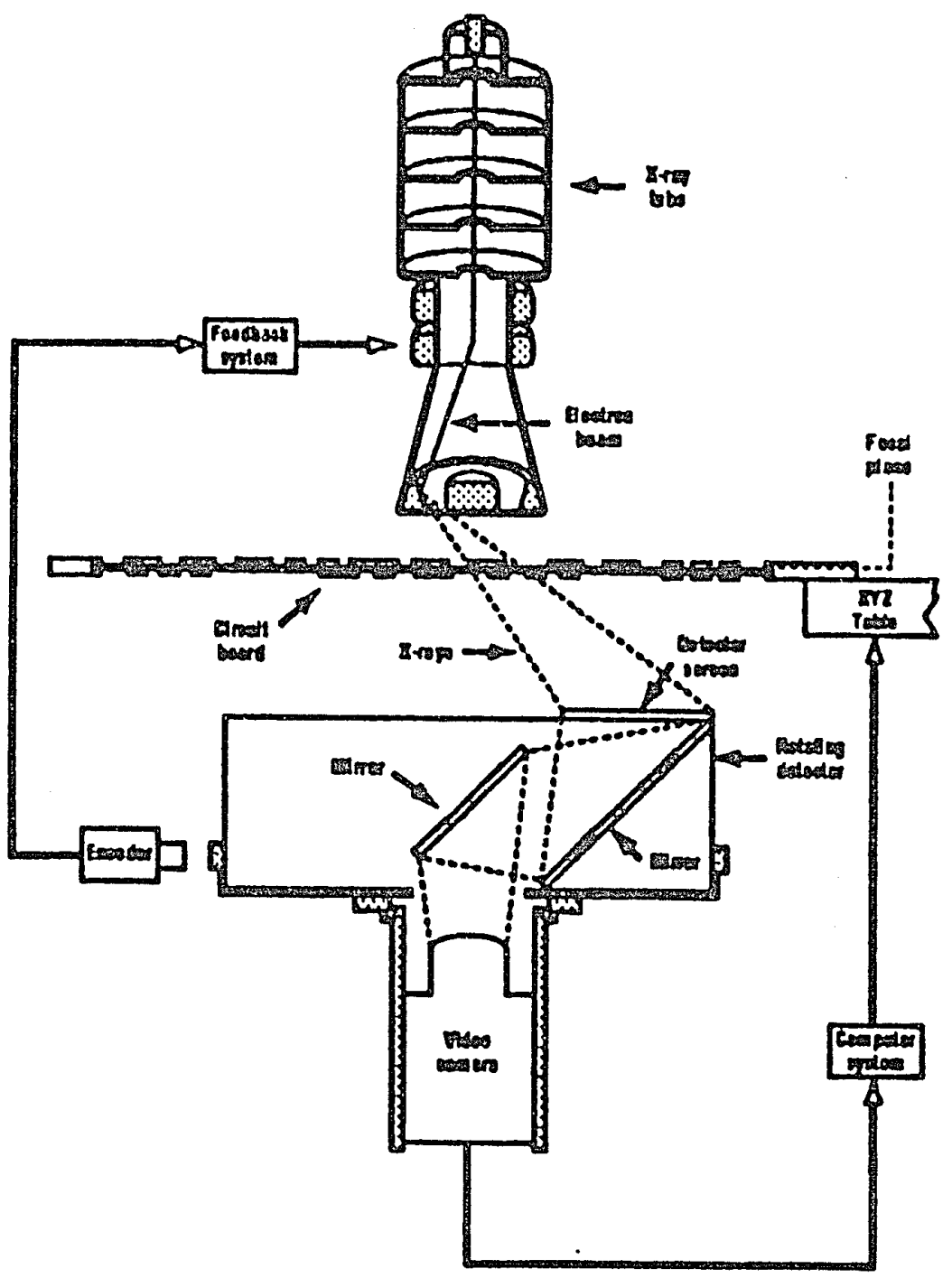

Figure 4. Schematic layout of the X-ray laminography machine.(Preskitt 1991) 


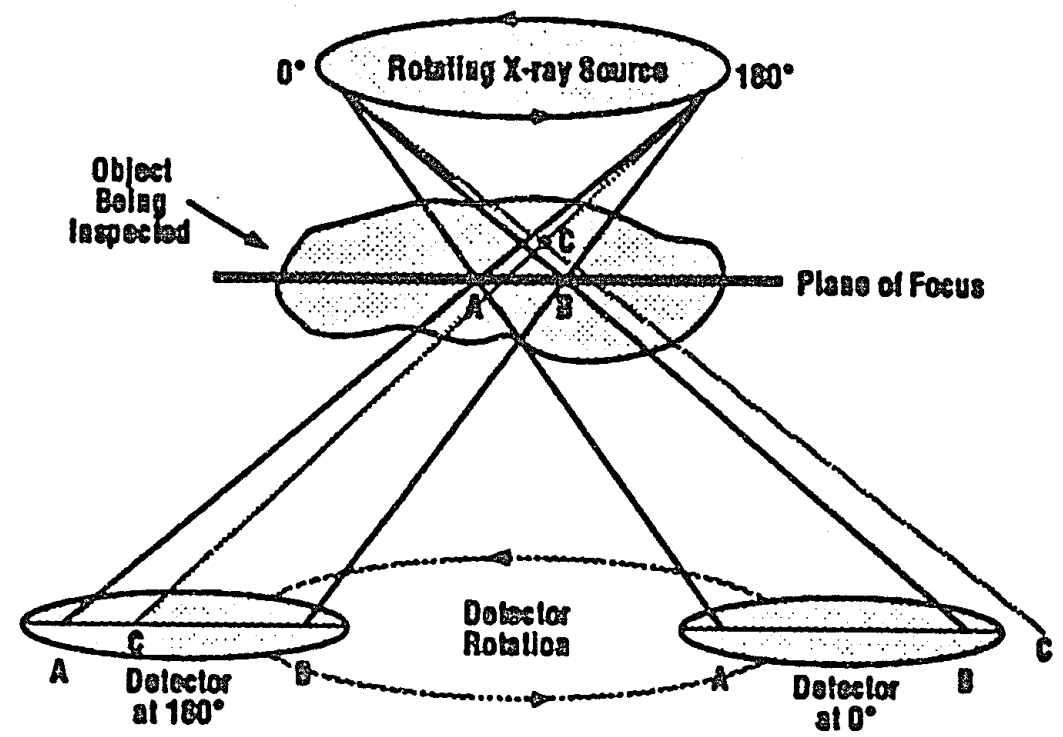

Figure 5. An illustration of the $X$-ray laminography focusing principle.(Preskitt 1991)

X-ray laminography is particularly suitable as a joint inspection technique for this study since it addresses several problems associated with MQFPs. The slicing feature of this machine provides the solution to the visual obstruction problem of the fillet of a gull-wing solder joint. High speed automation efficiently evaluates the joint quality of high lead count packages. In addition, processing of the acquired fillet geometry information is based upon a qualified model of quality. 


\section{MECHANICAL INTEGRITY OF SOLDER JOINTS}

\subsection{Process Parameters and Mechanical Properties}

Reliability of a solder joint can be assessed by analysis of the fracture mechanism after undergoing destructive mechanical testing. Nakaoka, et al. ${ }^{(16)}$ investigated the joint interface properties and the mechanical strength as a function of solder volume of gull-wing lead, quad flat packages (QFPs) by peel testing. The lead material was Alloy 42 with a $12 \mu \mathrm{m}$ coating of $90 \% \mathrm{Sn} / 10 \% \mathrm{~Pb}$ solder. The vapor phase reflow process was employed. Copper was the soldering land material and a $\mathrm{Sn}-\mathrm{Pb}$ eutectic paste was used. It was reported that the crack initiation occurred at the top heel of the fillet and propagated outward along the interface between the lead and the solder layer. SEM analysis revealed dimple rupture resulting from microvoid coalescence. The strength of the solder joint was reported to be an increasing function of solder paste thickness up to a thickness of $160 \mu \mathrm{m}$ where it leveled off to a constant strength value.

Chen ${ }^{(17)}$ conducted a two-level, three-parameter factorial design experiment to determine the controlling parameter with respect to the pull strength and the shear strength of a solder joint. The process parameters were solder paste thickness, lead/pad geometry, and circuit board placement misalignment. The specimens tested were the 44 and $68 \mathrm{C}$-quad packages which corresponds to the two levels of lead/pad geometry. The levels chosen for the paste thickness parameter were values within the scope of the mathematical model employed for the stress predictions. The levels chosen for the misalignment factor were within typical tolerances. The factorial design model for 
the pull strength predicts, in decreasing order of effect significance, lead/pad geometry, paste thickness, and component misalignment. The model for the shear strength also predicted lead/pad geometry to be the dominating factor, but paste thickness and component misalignment were equally important. The factorial design methods were to be employed in this study in order to establish the hierarchy of effects of the factors of reflow time-temperature profile, lead noncoplanarity, and solder paste system type.

\subsection{Mechanical Reliability Under Cyclic Loading}

Surface mounted assemblies were cycled to failure by mechanical vibration testing by Lau, et al. ${ }^{(18)}$ Test boards of FR-4 epoxy/glass were prepared with 68 and 84 lead Plastic Leaded Chip Carriers (PLCCs) with J type lead configurations, and 132 lead PQFPs and 160 lead QFPs with gull-wing leads. These boards were subjected to in-plane and out-of-plane (with respect to the board) vibration and shock tests. The in-plane vibration tests utilized a mechanical shaker with random frequency sweeps from 5 to $2000 \mathrm{~Hz}$. Results showed no lead failure in all cases with a test duration of 7.5 hours. The results for the in-plane shock tests, in which the specimens were vertically dropped with a maximum velocity of $304 \mathrm{in} / \mathrm{sec}$, also showed no lead failure. The excitation frequencies of the test boards were estimated with a mathematical model and determined to be in the range of $60 \mathrm{~Hz}$ to $70 \mathrm{~Hz}$.

For out-of-plane vibration tests, the shaker table was set to perform sweeps from $60 \mathrm{~Hz}$ to $90 \mathrm{~Hz}$ and lead joint contacts were monitored for electrical continuity by wiring to an automated data acquisition device. In a general assessment of all cases, the onset of joint failure was observed at a test duration 
of 6 hours, corresponding to 1.6 million cycles. Statistical analysis of the data at 8 million cycles with a Wiebull distribution model and a $90 \%$ confidence level showed a reliability of $13 \%$ for the 68 lead PLCC, $23 \%$ for the 132 lead PQFP, $30 \%$ for the 84 lead PLCC, and $2.4 \%$ for the 160 lead QFP. Figure 5 is a plot of the distribution for the 160 lead QFP tests. The specimens used in the out-ofplane vibration tests were also used in the out-of-plane shock tests and the results were determined to be inconclusive.

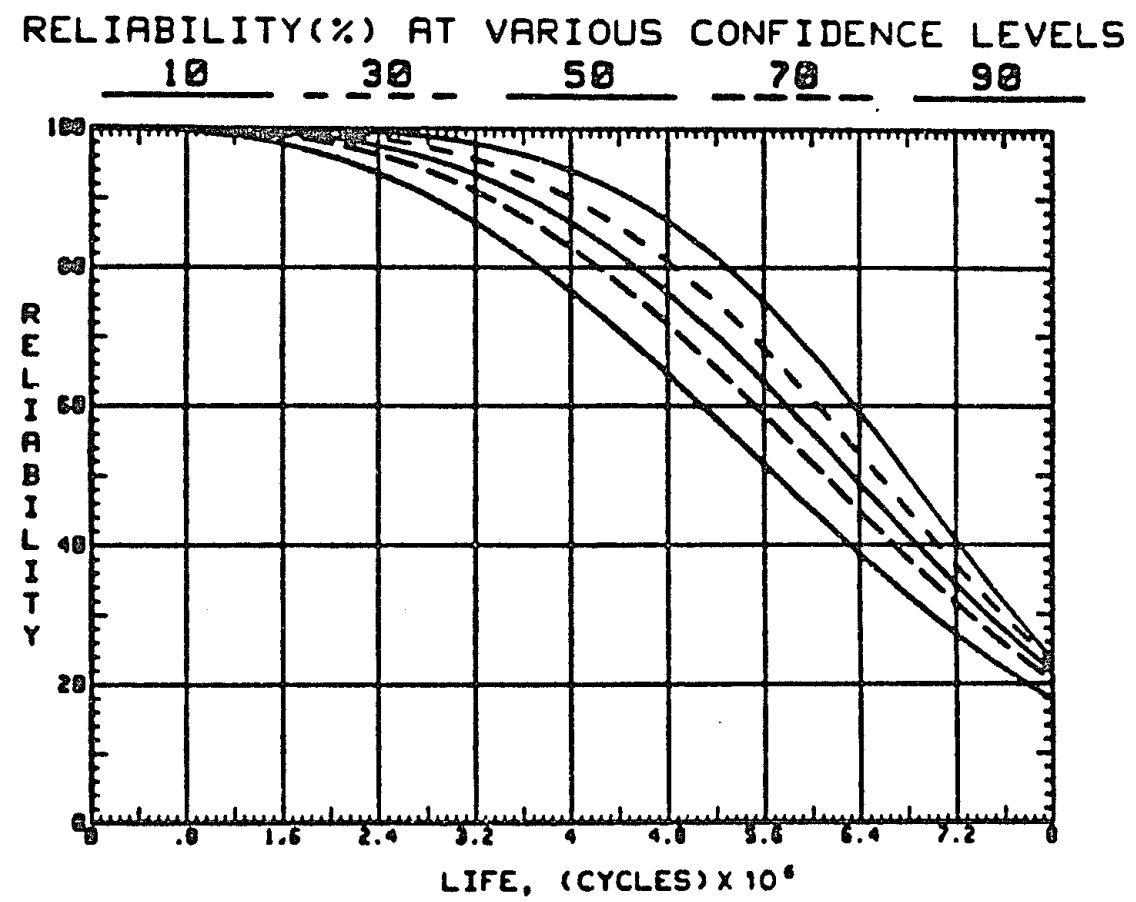

Figure 6. A distribution of reliability under vibration loading of SMT solder joints. (Lau, 1989)

A processed joint known to have a poor process history and therefore poor integrity should shift this distribution toward a lesser number of stress cycles to failure. The shape of the distribution may be altered depending on the source and mechanism of failure. 


\section{RESEARCH HYPOTHESIS}

Process factors determine the mechanical integrity of a fine pitch surface mount solder joint. These factors include the process variables of reflow timetemperature profile and characteristics of the solder paste employed.

Fine pitch surface mount solder joints with low mechanical integrity will fail under mechanical cyclic loading at a greater rate than those of high integrity.

Vibration testing can provide information that will correlate process history to the mechanical properties of fine pitch surface mount assemblies. There is a potential of applying vibration testing as a process verification tool. 


\section{EXPERIMENTAL METHODOLOGY}

\subsection{Overview}

This study consists of two aspects of fine pitch surface mount assemblies: the effect of process parameter on joint integrity and the behavior of the assemblies under sinusoidal out-of-plane mechanical loading. Four sets of assemblies were investigated. One set was processed under controlled reflow conditions and analyzed. This set was designated A.1 and A.2, the extension being to denote their respective reflow conditions: a typical condition and an extreme condition. Specific process conditions will be described in greater detail in subsection 5.2.1. The remaining sets, which did not have documented process histories, were designated Types $B, C$, and $D$, respectively. Table 4 lists the various sets of assemblies and describes the out-of-plane vibration testing conditions imposed on each type.

Table 4. Various Test Conditions for Assemblies Investigated

\begin{tabular}{|c|c|c|c|c|c|}
\hline Designation & $\begin{array}{l}\text { Frequency } \\
(\mathrm{Hz})\end{array}$ & Acceleration (g) & $\begin{array}{l}\text { Duration } \\
\text { (hr's) }\end{array}$ & \# of cycles & Method \\
\hline A.1 and A.2 & 60 & 12 & 6 & $1296 \mathrm{~K}$ & EM \\
\hline $\mathrm{B}$ & 280 & 12 & $>9$ & $>9072 K$ & EM \\
\hline C & 22-32 sweep & 1.78 & 8.33 & $810 \mathrm{~K}$ & $\mathrm{SH}$ \\
\hline D & 22-32 sweep & 0.875 & 18 & $1749 \mathrm{~K}$ & $\mathrm{SH}$ \\
\hline
\end{tabular}




\subsection{Preparation and Vibration Testing of the Assemblies}

\subsubsection{Type A.1 and A.2 Assemblies}

The A.1 and A.2 assemblies were identical in construction but differed in their respective time-temperature reflow process histories. These assemblies were designed to facilitate data acquisition of the time to failure data during the out-of-plane vibration fatigue testing. The packages used in these assemblies were 160 lead MQFPs in which each adjacent I/O was internally daisy chained (alternating inner bonding fingers were electrically connected). The external lead pitch was $0.65 \mathrm{~mm}$ and the body size was $28 \mathrm{~mm} \times 28 \mathrm{~mm}$. The leadframe material was copper alloyed with nickel, silicon, and magnesium (specific composition proprietary). A $85 \% \mathrm{Sn} / 15 \% \mathrm{~Pb}$ solder coating with a thickness of approximately $50 \mu \mathrm{m}$ was electroplated on the leads.

The test boards were constructed of FR-4 with copper lands. The dimensions of the boards were basically that of a 5.25" by 5.25 " ( $13 \mathrm{~cm}$ by 13 $\mathrm{cm}$ ) square with a two sided $80 \mathrm{l} / \mathrm{O}$ card edge connector protruding on one side. A schematic is given in Figure 7. A typical commercial water soluble solder paste (Alpha Metals Water-soluble Aqualine $63 \mathrm{Sn} / 37 \mathrm{~Pb}$ ) was used. The paste was applied through a stencil on a Fuji GL II machine and the packages were hand loaded for assembly. 


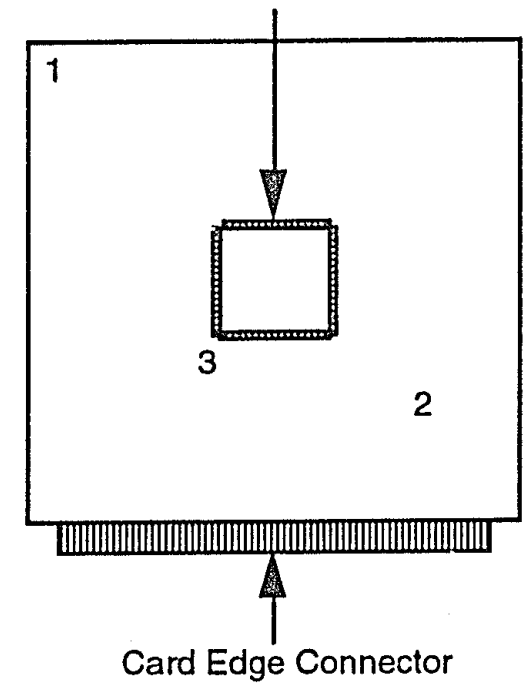

1: on board edge, farthest from package

2: a distance between package and board edge

3: close to package

Figure 7. An illustration of the A.1 and A.2 test boards.

The A.1 assemblies were reflowed in an infrared (IR) oven using an existing time-temperature profile known to provide good solder joints for boards of a similar size. The A.1 profile is a two-peak system. The first peak is one which does not reach the eutectic temperature but is selected such that the flux deoxidizes the soldering surfaces effectively. The second peak is the soldering peak in which the temperature does exceed the eutectic temperature and reflow occurs. The A.2 assemblies underwent a profile designed to promote defect formation. It is a single broad peak system with a longer dwell time above the eutectic temperature. The longer dwell time was intended to promote intermetallic formation.(19) The altered parameters and their hypothesized effects for the A.2 group are described in Table 5. 
Table 5. The Altered Parameters of the A.2 Assemblies

Altered Parameter Hypothesized Effect

high conveyor speed promotes inadequate fluxing action

low initial peak temperature promotes inadequate fluxing action

high final peak temperature promotes excessive intermetallic formation

The two sets of assemblies were reflowed with an infrared oven, the Vitronics SMD 722, which provided ten zones of temperature programmability. The system employed an external bank of muffin style cooling fans at the oven's exit point for cooling control. The nominal temperature set points and conveyor speeds for each set of assemblies are listed in Table 6.

Table 6. Nominal Temperature Set Points and Conveyor Speed for the A -Series Assemblies

\begin{tabular}{lll}
\hline Zone \# & Temperature $\left({ }^{\circ} \mathrm{C}\right)$ & Temperature $(\bar{\circ} \mathrm{C})$ \\
& A.1 Assemblies & A.2 Assemblies \\
\hline 1 & 270 & 200 \\
2 & 270 & 200 \\
3 & 280 & 200 \\
4 & 220 & 215 \\
5 & 200 & 225 \\
6 & 200 & 250 \\
7 & 200 & 300 \\
8 & 205 & 325 \\
9 & 280 & 350 \\
10 & 370 & 380 \\
\hline Conveyor Speed & $64.9 \mathrm{~cm} / \mathrm{min}$. & $90 \mathrm{~cm} / \mathrm{min}$. \\
\hline
\end{tabular}


Time-temperature monitoring during the A.1 and A.2 reflow process was achieved by the use of a self contained data acquisition unit: the Electronic Controls Design Inc. Super-M.O.L.E. Thin Line. The unit follows the assemblies through the oven on the conveyor during the reflow process and accepts up to six thermocouple inputs. However, in these experiments, three were utilized. The various locations of placement of the type $\mathrm{K}$ (chromel-alumel) thermocouples on the test boards are shown as location 1,2, and 3, respectively, in Figure 7. These locations were chosen in order to investigate the effect of component density in a controlled manner in a nearly symmetrical assembly. The thermocouples were inserted into metal plated test vias and attached by Kapton tape.

The A.1 and A.2 assemblies were cleaned after the reflow cycle in a Stoelting CBW-224 Aqueous Cleaner at a wash temperature of $68.3^{\circ} \mathrm{C}\left(155^{\circ} \mathrm{F}\right)$ and a drying temperature of $110^{\circ} \mathrm{C}\left(230^{\circ} \mathrm{F}\right)$ in order to remove solder paste residuals from the joints. The recorded time-temperature profiling data from the data acquisition unit were transferred to a MS-DOS computer with the appropriate accompanying software. The data were written into text files and analyzed. The Type A.1 and A.2 assemblies were examined by scanned-beam laminography with an instrument by $4 \Pi$ Systems ${ }^{*}$ in order to characterize the representative defect state.

The Types A.1 and A.2 assemblies were subjected to out-of-plane vibration testing by affixing the structure to a bench top electromagnetic shaker

\footnotetext{
* 4 ПI Systems of San Diego, CA
} 
table similar in operating principle and size of a typical audio loudspeaker. The layout of this equipment is depicted in Figure 8.

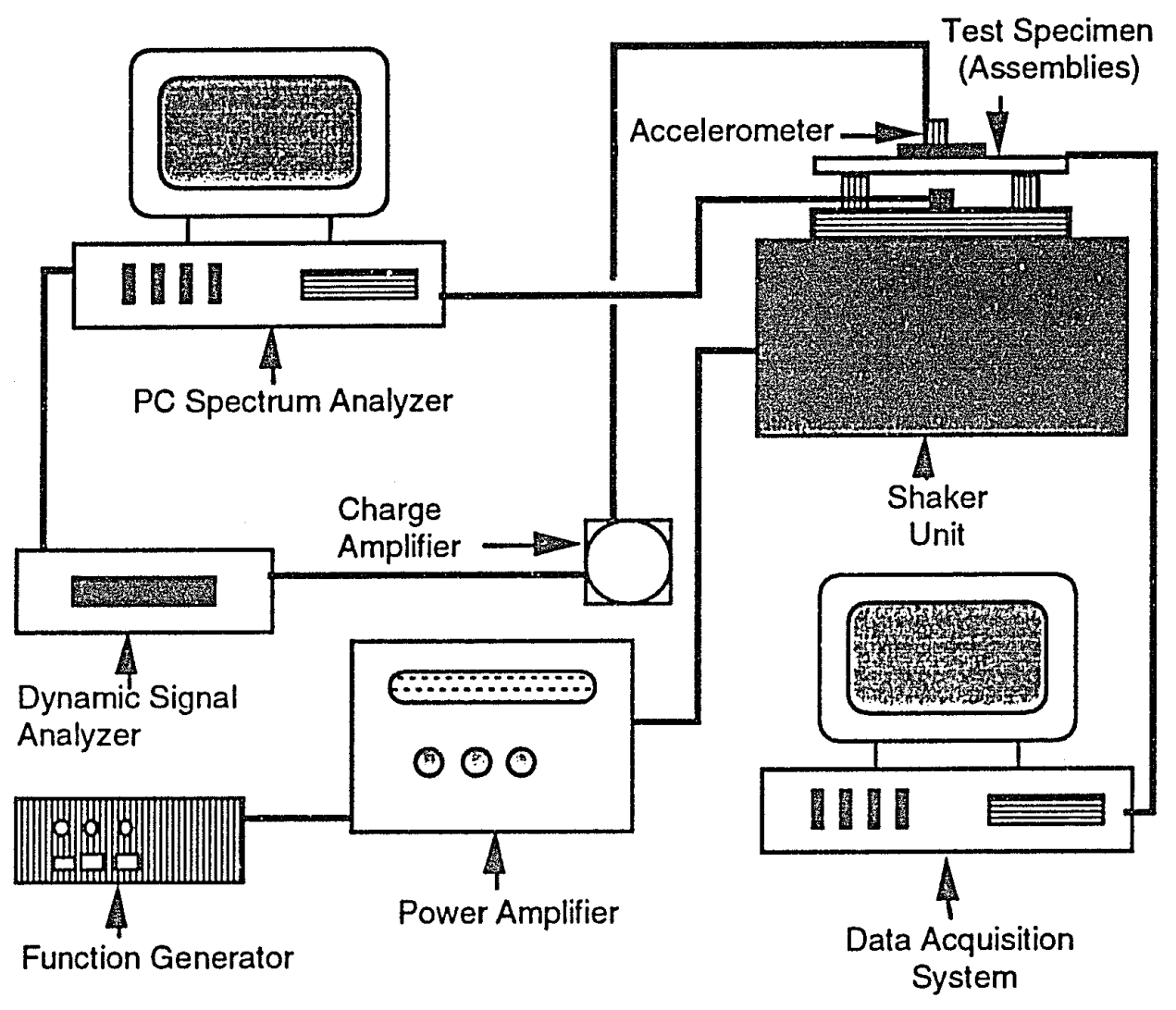

Figure 8. A diagram of the vibration testing system.

A. data acquisition system applicable only to the Type A.1 and A.2 assemblies whose boards were custom designed and fabricated for this purpose, detects lifted leads by recording an open circuit of a pair of internally daisy chained leads during the vibration test. The software tracks such activity as a function of lead number and test duration. Since in all probability that the a lifted 
lead may contact the land and close the circuit, the system does not record an "open" until ten such events occur in succession. A shortcoming of this system is that it can only detect failure of an adjacent lead pair. It cannot identify which lead, or perhaps both, of the pair is causing the open circuit.

The Types A.1 and A.2 assemblies were affixed to the shaker table as shown in Figure 9 and tested at $60 \mathrm{~Hz}$ for 6 hours. The number of open circuits with respect to time was recorded by the data acquisition system. After a series of tests in this manner, it was determined that the system was faulty. While the software was recording open circuits and with a distribution with respect to time, exhaustive metallography and microscopy did not reveal any correlating visual evidence of cracked or lifted leads. It was later found that the open circuits occurred at the wiring harness on the card edge connector. A more robust harness or an alternative wiring scheme would be required for future work with this system.

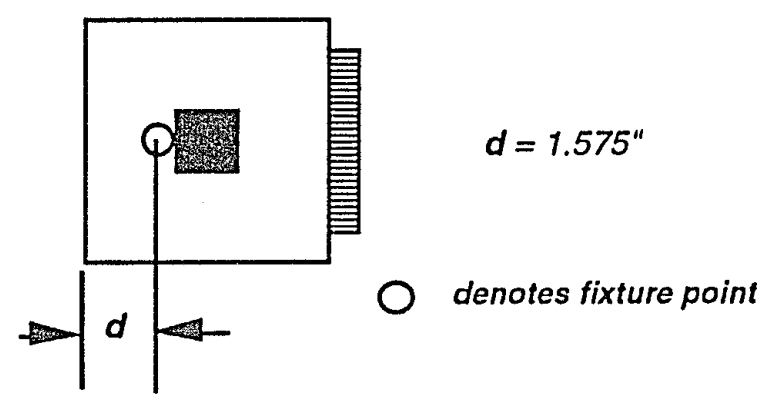

Figure 9. An illustration showing the attachment point for the vibration testing of the A.1 and $A .2$ assemblies.

The original goal was to make extensive use of the specially designed Type A.1 and A.2 test boards and the electromagnetic shaker unit to obtain 
quantitative reliability data. However, funding and logistical problems required an alternative approach. Commercial assemblies with high lead count packages were obtained from the industry and a large servo-hydraulic vibration tester was employed. The servo-hydraulic testing of the Type $C$ and $D$ assemblies is described in subsection 5.2.3.

\subsubsection{The Type B Assemblies}

The Type $B$ assemblies consist of a printed circuit board with 2 packages of the 132 lead JEDEC QFP variety with an external lead pitch of 25 mils $(0.635$ $\mathrm{mm}$ ) and corner bumpers. The layout is shown in Figure 10. The dimension of the board was $5.25^{\prime \prime}$ by $5.25^{\prime \prime}(13 \mathrm{~cm}$ by $13 \mathrm{~cm})$. The leadframe material was copper. The packages were hand soldered to an off the shelf ${ }^{*}$ FR-4 test board with copper lands. Rosin core solder of the lead-tin eutectic composition was used. These assemblies were vibration tested with an electromagnetic shaker table without a fixed number of cycles prior to testing. The procedure continued until visual evidence of lifted leads were observed. The specific excitation conditions are shown in Table 4. The fracture surfaces were examined by scanning electron microscopy following out-of -plane vibration testing.

\footnotetext{
* Provided by Solectron Corp. of Milpitas, CA
} 


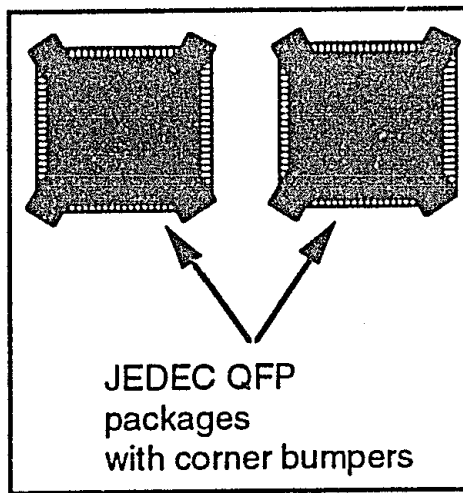

Printed Circuit Board

Constructed of FR-4

Figure 10. Schematic of the B assemblies.

\subsubsection{Type $C$ and D Assemblies}

Type $C$ and $D$ sets assemblies are large commercial assemblies typical of a control card in a commercial laser printer. The dimensions of these rectangular assemblies are $13^{\prime \prime}$ by $8^{\prime \prime}(33 \mathrm{~cm}$ by $20 \mathrm{~cm})$. On each of these assemblies were two fine pitch packages that were utilized in this study. Both packages are identical in construction; both are 208 lead MQFPs with external lead pitches of $0.5 \mathrm{~mm}$. They differ in their respective leadframe materials. One was made of a copper alloy and the other Alloy 42. The side of each package with respect to its position on the board was carefully tracked in all subsequent analytical procedures due to the vast asymmetry of these assemblies. The respective sides were designated as I, II, III, and IV. Their relative positions on the printed circuit board is given in Figure 10. A number of other packages were on these assemblies and include a different type of MQFP, Thin Quad Flat Packs (TQFPs) and a JEDEC QFP with corner bumpers. A diagram of these assemblies with the approximate relative size and location of each package on the printed circuit board is given in Figure 11. Only the 208 lead MQFPs are applicable to this study. However, the presence of the other packages play a role in thermal 
distribution during reflow. These assemblies were processed under standard commercial IR reflow conditions.

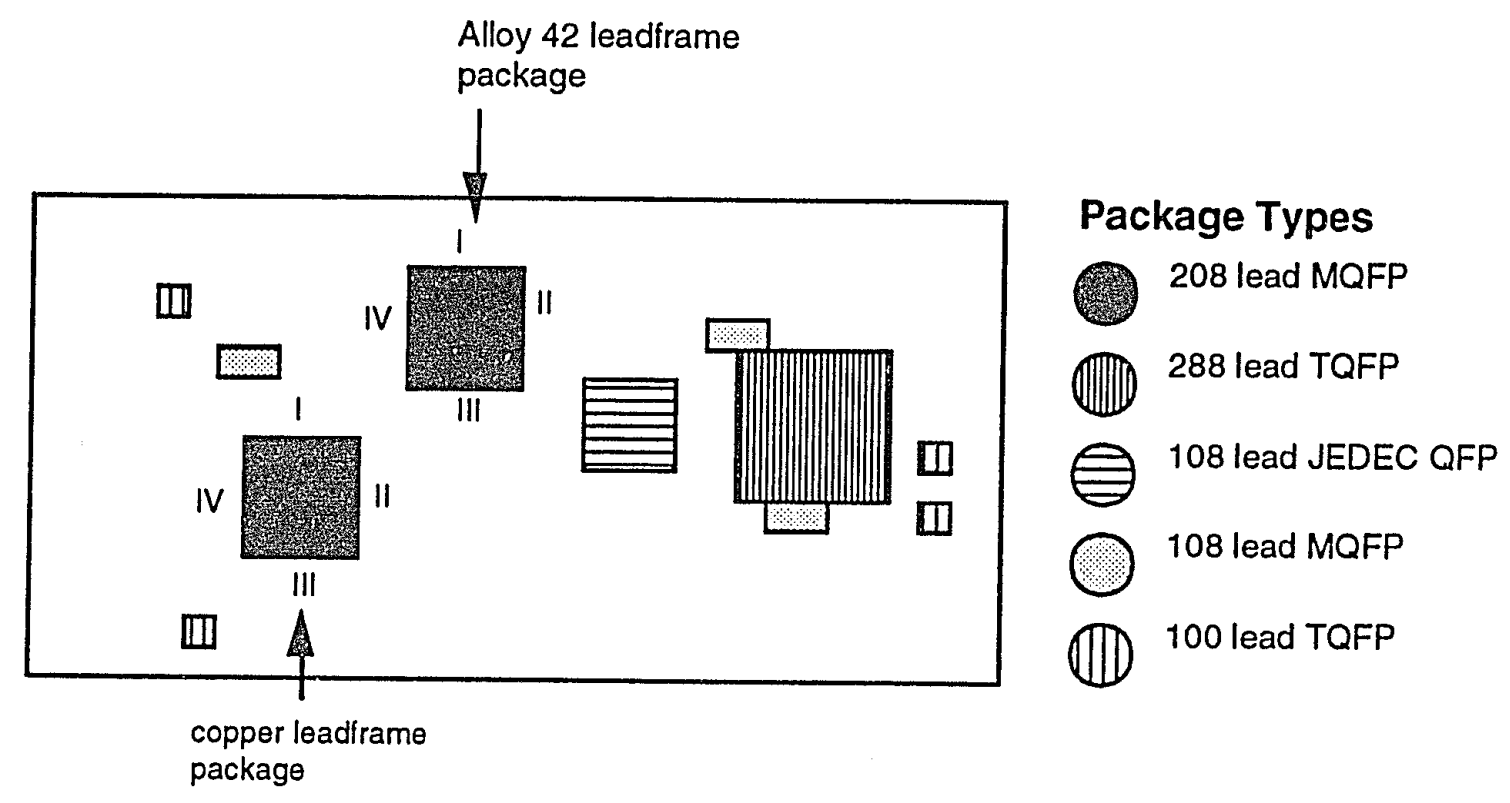

Figure 11. The layout of the $C$ and $D$ assemblies.

The Type $C$ and $D$ assemblies were tested with a hydraulically driven shaking unit, the MTS $840^{*}$. These assemblies were affixed through a hole on the center of the boards. A different set of testing parameters were employed for the $C$ assemblies than for the $D$ assemblies.

The $C$ assemblies were subjected to large accelerations with a short number of cycles: $1.78 \mathrm{~g}$ 's $\left(17.4 \mathrm{~m} / \mathrm{s}^{2}\right)$ and 810,000 cycles, respectively. Those corresponding values for the $D$ assemblies are $0.875 \mathrm{~g}$ 's $\left(8.6 \mathrm{~m} / \mathrm{s}^{2}\right)$ and 1749,000 cycles, respectively. Both sets were tested with a sinusoidal frequency sweep from $22 \mathrm{~Hz}$ to $32 \mathrm{~Hz}$ at a sweep rate of $1 \mathrm{~Hz} / \mathrm{sec}$.

\footnotetext{
${ }^{*}$ MTS Systems of San Jose, CA
} 
It should be noted that comparisons of results obtained with the electromagnetic shaker to those obtained with the servo-hydraulic are indirect and should be regarded as broad assertions. The differences in loading dynamics due to the variations in dimension of the assemblies and the distinctive nature of the respective testing systems will allow only limited comparison.

\subsection{Destructive Examination of Failed Assemblies}

Several general metallographic procedures were applied to all four types of assemblies. Each high lead count package of interest was initially removed from the printed circuit board with a small precision high-speed circular saw, leaving approximately $1 \mathrm{~cm}$ of board trim protruding from the edge of the package leads. Specimens were further sectioned using a low-speed metallography diamond saw to obtain either a lead profile or a frontal polish. A typical example of a profile polish is depicted in Figure 12. The profile polish is intended for observing longitudinal details. A frontal polish is a transverse section of a lead as viewed from a package side and one mount encompasses all leads on a given package side. This type of polish is useful for collection of statistical information of crack and void density. An example of a transverse section is shown in Figure 13.

All specimens were mounted in clear epoxy. Grinding was performed in succession utilizing $120,220,320,400$, and 600 grit SiC abrasive paper. Polishing was accomplished using in succession of 6,3 , and $1 \mu \mathrm{m}$ diamond paste on nylon. The solder etchant used in all cases was a $\mathrm{Pb}$ phase selective 
solution consisting of four parts glycerol, one part acetic acid and one part nitric acid.

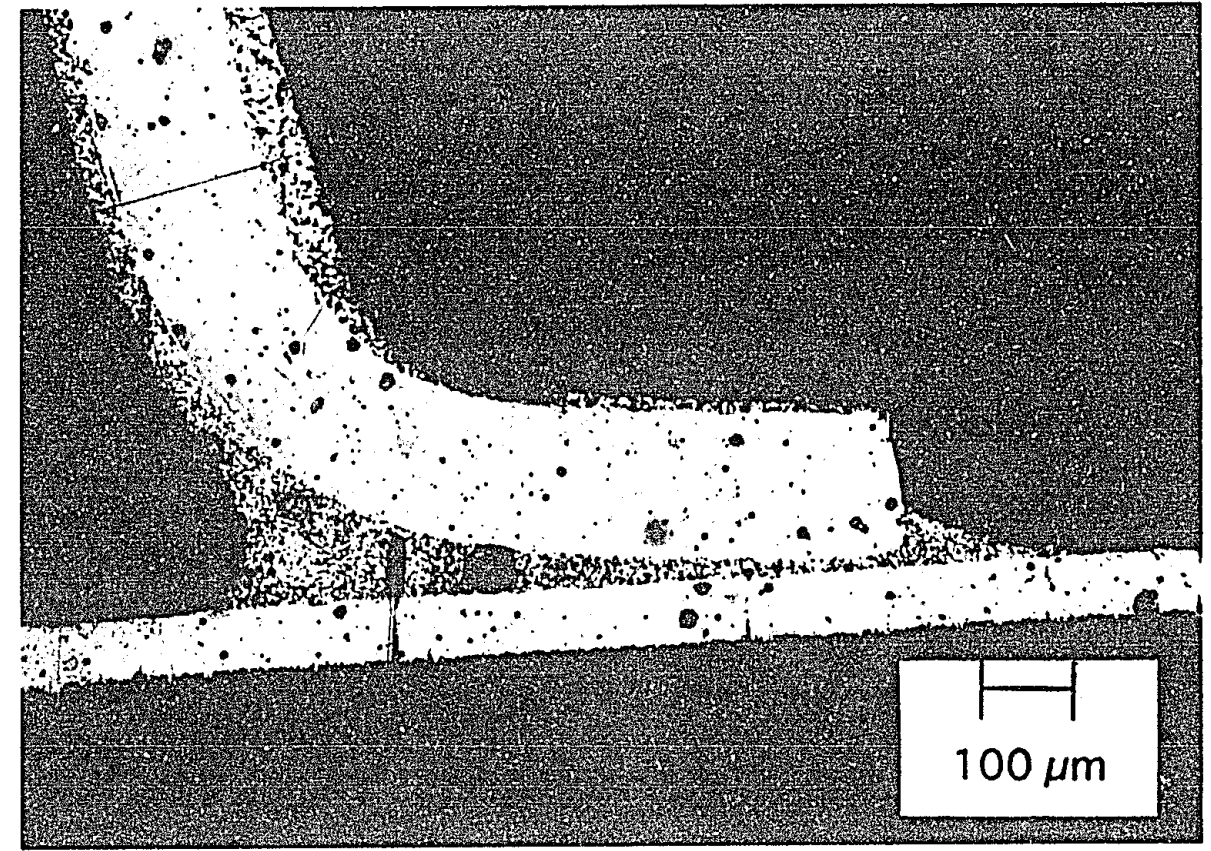

Figure 12. A micrograph of a typical mounted assembly that was prepared by a lead profile polish. This is a 160 lead $0.65 \mathrm{~mm}$ pitch MQFP at $100 \mathrm{x}$ magnification. 


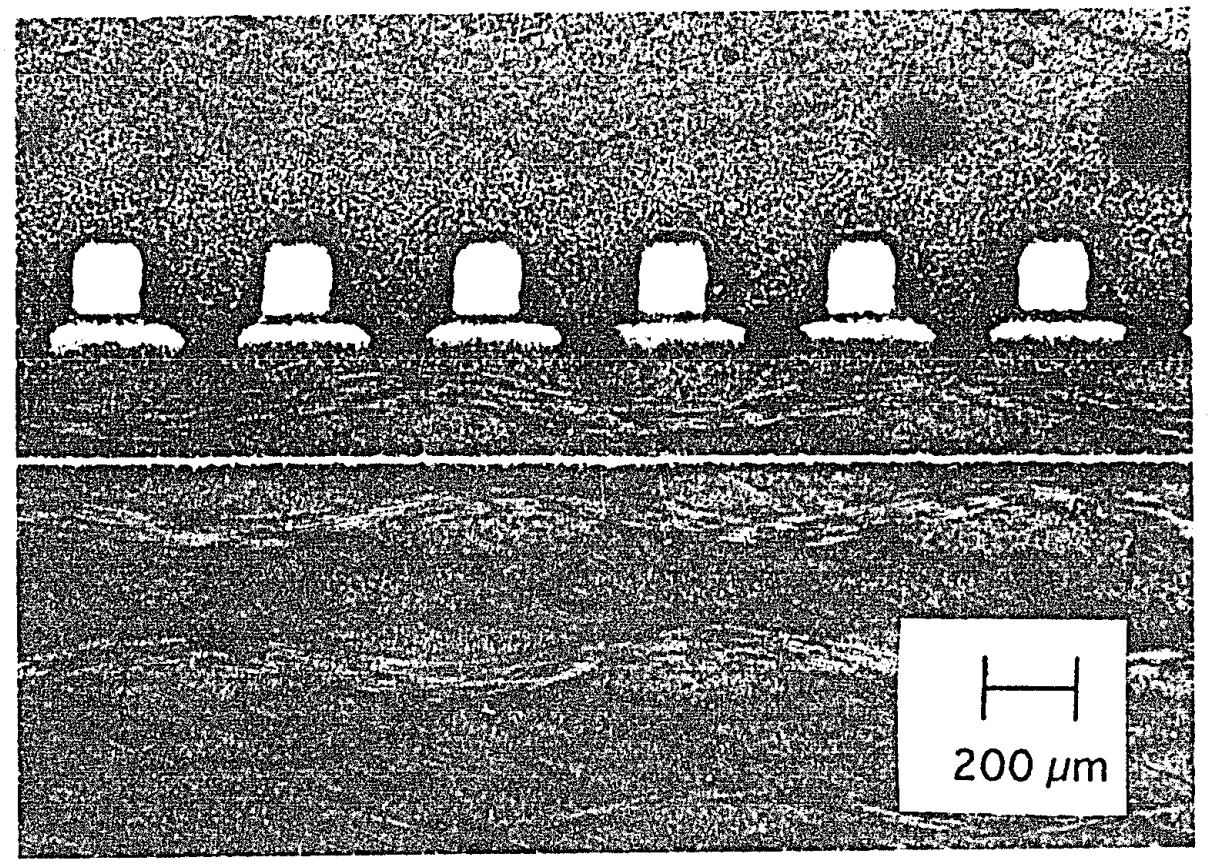

Figure 13. Photomicrograph of a transverse section of a 208 lead $0.50 \mathrm{~mm}$ pitch MQFP at $50 \mathrm{x}$ magnification.

One of the intentions of performing metallography on the A.1 and A.2 assembly sets was to correlate lead failure data as reported by the data acquisition system to the metallurgical condition of the corresponding solder joint(s). The data acquisition system should identify failed lead locations on the package and the metallography provides for visual verification of a crack or lifted lead. However, in the initial vibration testing of the A.1 and A.2 assemblies, the metallography served to disprove the validity of the collected data. No cracks were discovered in areas where the data acquisition indicated clusters of open circuits. Many lead profile polishes were performed in a depth profiling procedure of the entire cluster and showed no correlation. In addition, frontal polishes were 
performed and showed no corresponding physical lead separation. Further analysis indicated that intermittent failures were occurring in the wiring harness on the card edge connector resulting in the open circuits recorded by the data acquisition system.

Longitudinal polishes were performed on the Type B Assemblies to investigate crack mechanism as the presence of cracks in the solder joints were visually confirmed during the vibration testing procedure. Additionally, the fracture surfaces of the individual leads were examined for fracture details.

A frontal transverse section polish of each side of each Type $C$ and $D$ package of interest (208 lead copper MQFP) was performed. This procedure was executed to obtain statistical information of cracks due to vibration testing and voids which may occur during the commercial reflow process. A longitudinal profile of one lead on each side of each package was performed for purposes of potentially obtaining visual information in greater detail. Several leads of the Alloy 42208 lead MQFP were longitudinally sectioned and polished for inspection. 


\section{RESULTS}

6.1 The Effects of Changes in the Reflow Time-temperature Profile

\subsubsection{Process Temperature Variations for the Type A.1 and A.2 Assemblies}

The effect of component density of a given assembly on actual temperature is evident by inspection of the time-temperature profiles of the A.1 and the A.2 assemblies, given in Figures 14 and 15, respectively. Temperatures measured closer to the center of the assembly, where component density is greatest, are consistently higher than those measured closer to the edge. Another notable feature of these plots is the tendency for the more dense areas to reach peak temperatures earlier.

Since actual lead temperature is closest to that of location 3, comparisons between $A .1$ assemblies and A.2 assemblies will be restricted to those respective profiles which are plotted in Figure 16. There are two distinct peaks on the A.2 profiles (the typical condition); one occurring at approximately 125 seconds and another at 400 seconds, respectively, into the process. The first peak is at a temperature of $160^{\circ} \mathrm{C}$, roughly 20 degrees below the liquidus temperature of the solder. This peak is designed to allow the fluxes to provide a wettable surface for good solderability. The second peak, at $250^{\circ} \mathrm{C}$ was intended to melt (i.e. reflow) the metal powders within the paste. By comparison, there is no equivalent "fluxing" peak in the reflow of the A.2 assemblies. This extreme condition profile generally ramps straight to the maximum temperature of $230^{\circ} \mathrm{C}$. The result is one broad peak rather than two sharper ones. Additionally, the A.1 profile has a longer hold time below the eutectic temperature. 


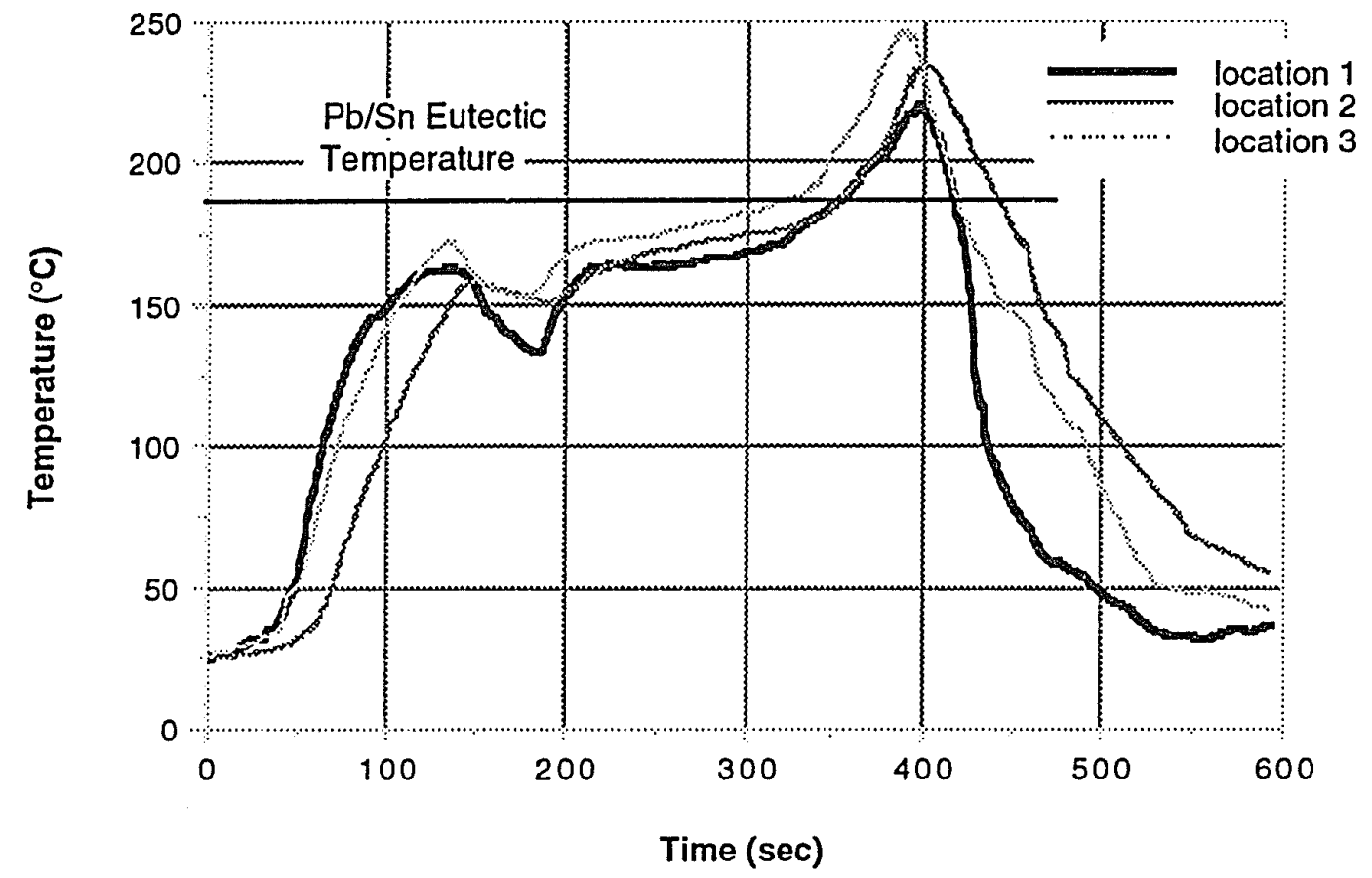

Figure 14. The time-temperature profiles of the A.1 (typical condition) assemblies.Location 1 is the thermocouple attachment point closest to the edge of the assembly and location 3 is the point with greatest proximity to the center. 


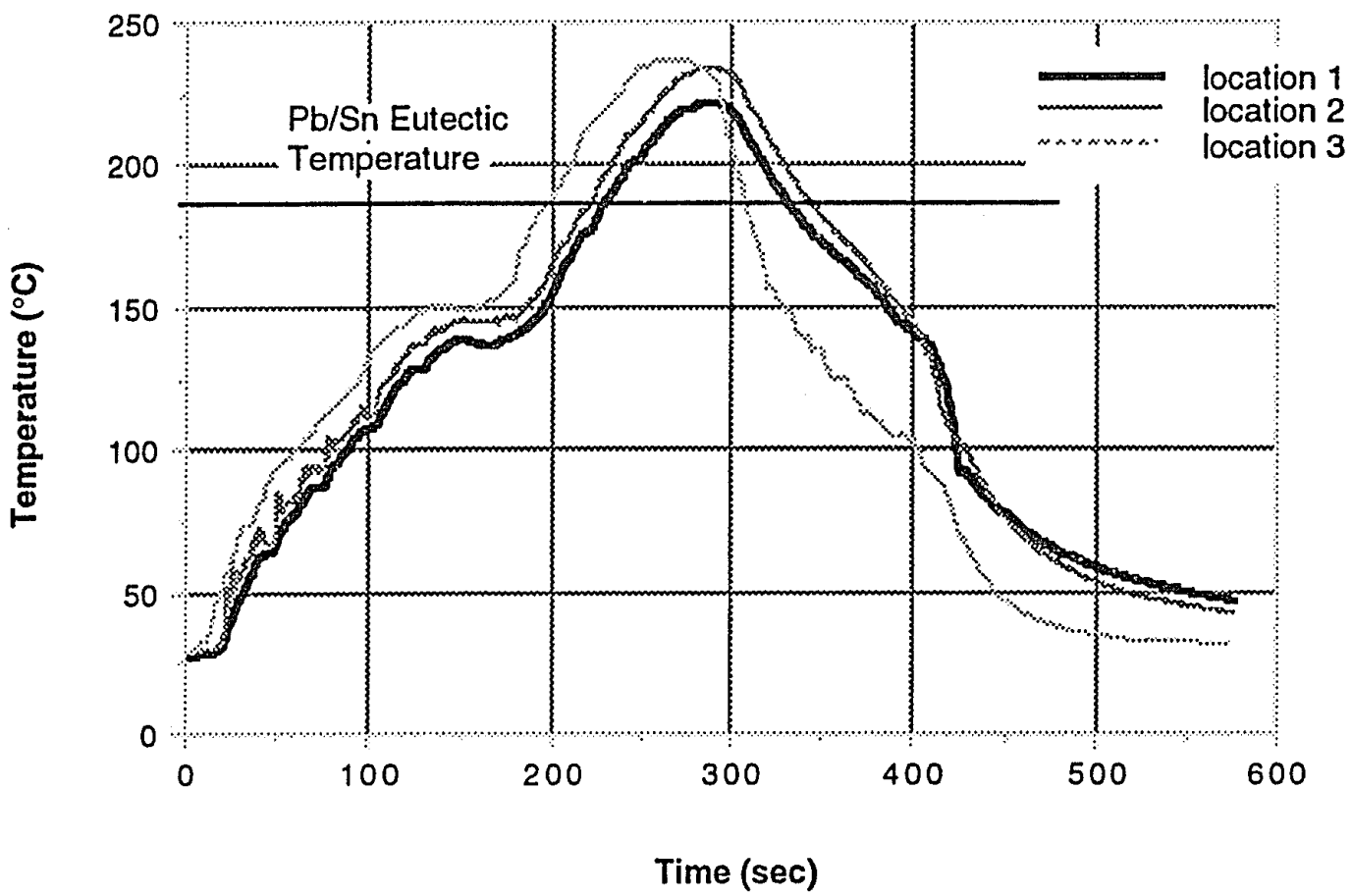

Figure 15. The time-temperature profiles of the A.2 (extreme condition) assemblies. Analogous to Figure 14, location 1 is the thermocouple attachment point closest to the edge of the assembly and location 3 is the point with greatest proximity to the center.

The A.2 profile has a longer dwell time above the eutectic temperature than the A.1 profile: 110 seconds versus 65 seconds, respectively. Dwell time above the eutectic temperature plays a major role in determining the degree of intermetallic formation and growth. 


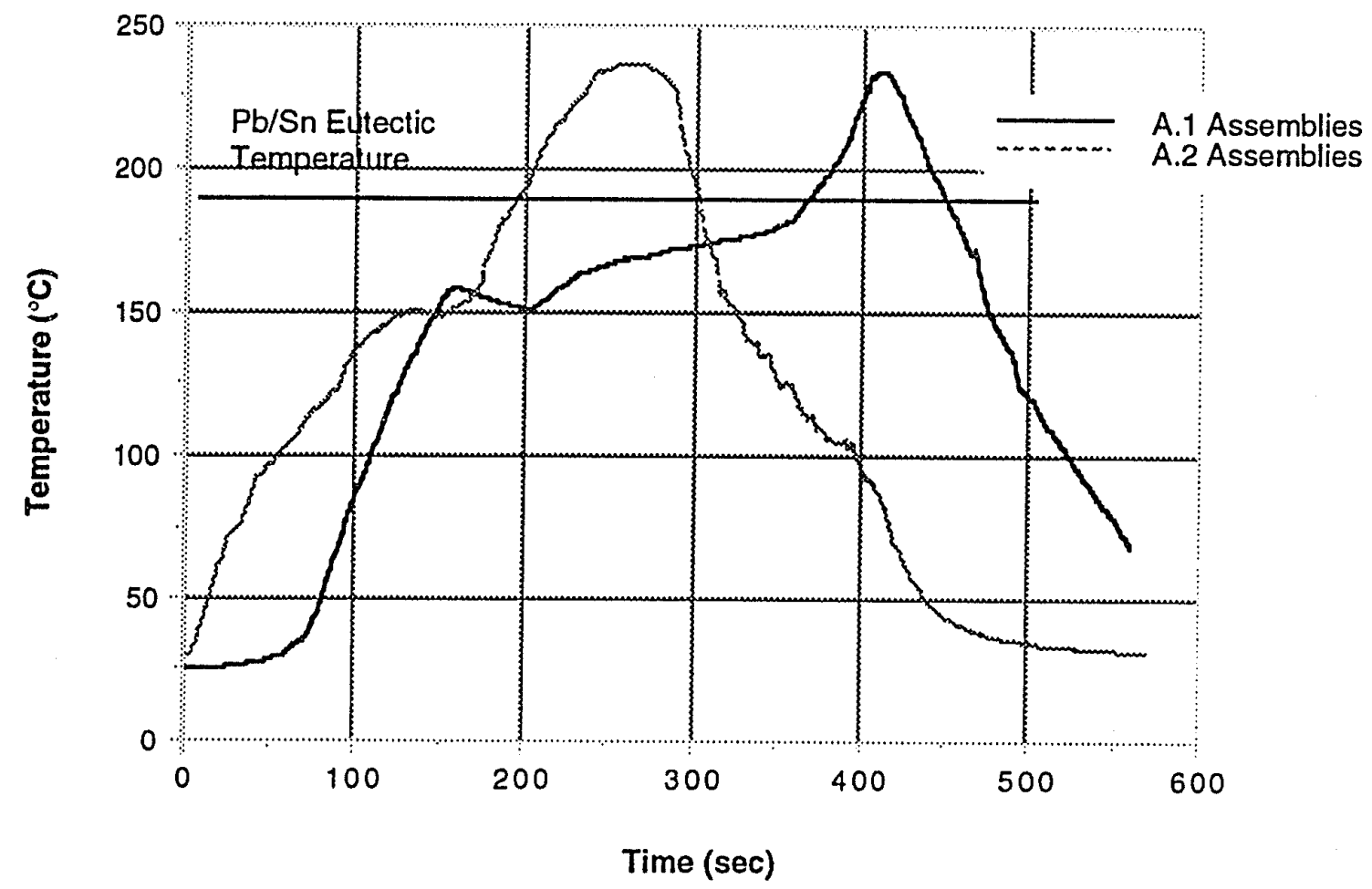

Figure 16. The superimposed location 3 (closest to center) time-temperature profiles of the A.1 and A.2 assemblies.

\subsubsection{X-ray Laminography of the A.1 and A.2 Assemblies}

Analysis of the group A.1 assemblies via X-ray laminography (scanned beam Laminography) reported no deviation from accepted values for "acceptable" solder joints. The system software measures the toe and heel of the fillet to determine acceptability. Excessive toe is defined by $4 \Pi$ Systems, the manufacturer of the instrument, as a toe height greater than that $0.057 \mathrm{~mm}$ (2.25 mils) unless the overall thickness of solder in the fillet is $150 \%$ in excess of nominal and thereby the system does not report the solder joint measurement as a defect. Similarly, excessive heel is defined as a heel height greater than that of 
$0.094 \mathrm{~mm}$ ( 3.71 mils) unless the overall thickness of solder in the fillet is $150 \%$ in excess of nominal. The overall average fillet thickness ${ }^{*}$ for the Type A.1 assemblies was found to be $0.069 \mathrm{~mm}$ ( 2.7 mils) with a standard deviation of $0.008 \mathrm{~mm}$ ( 0.33 mils) for 640 leads. Inspection by the instrument of the A.2 assemblies indicated a $8.1 \%$ occurrence of an excessive toe and a $2.8 \%$ result of an excessive heel for 320 leads.

\subsubsection{Intermetallic Formation of the A.1, A.2, C, and D Assemblies}

The A.1 and the A.2 assemblies were processed, as can be seen from inspection of Figure 16, with different dwell times above the eutectic temperature. The A.2 assemblies were exposed to a period above the eutectic temperature for a time 1.7 times greater than that of the A.1 assemblies. However, there is no apparent difference in $\mathrm{Cu}_{6} \mathrm{Sn}_{5}$ and $\mathrm{Cu}_{3} \mathrm{Sn}$ intermetallic layer thickness between the two processes. Measured average intermetallic thicknesses were found to be $4 \pm 1.5 \mu \mathrm{m}$ for both processes. Figure 17 is an optical micrograph of the lead solder interface region of an A.1 processed joint. The intermetallic layer is the high contrast region between the copper lead and the gray fillet. Figure 18 is a similar micrograph of a joint processed under A.2 conditions. Note that there is no observable change in thickness of the intermetallic layer between the two solder joints.

As can be gleaned from Figure 19, a micrograph of a Type C Assembly, the intermetallic layer is very uniform around the perimeter of the lead including the $85 \% \mathrm{Sn} / 15 \% \mathrm{~Pb}$ electroplated arm region. A feature of this layer, as can be seen via close inspection of Figure 17, is that the intermetallic layer is present, to a lesser degree, at a void/ lead interface. These results indicate that the

\footnotetext{
* Average fillet thickness is defined as the mean of the height of the heel, the center, and the toe of the fillet.
} 
thickness of $\mathrm{Cu}_{6} \mathrm{Sn}_{5}$ and $\mathrm{Cu}_{3} \mathrm{Sn}$ intermetallic formation and growth at the region contacting the void occurred during the electroplating process. The additional thickness found elsewhere on the lead is the product of the reflow process.

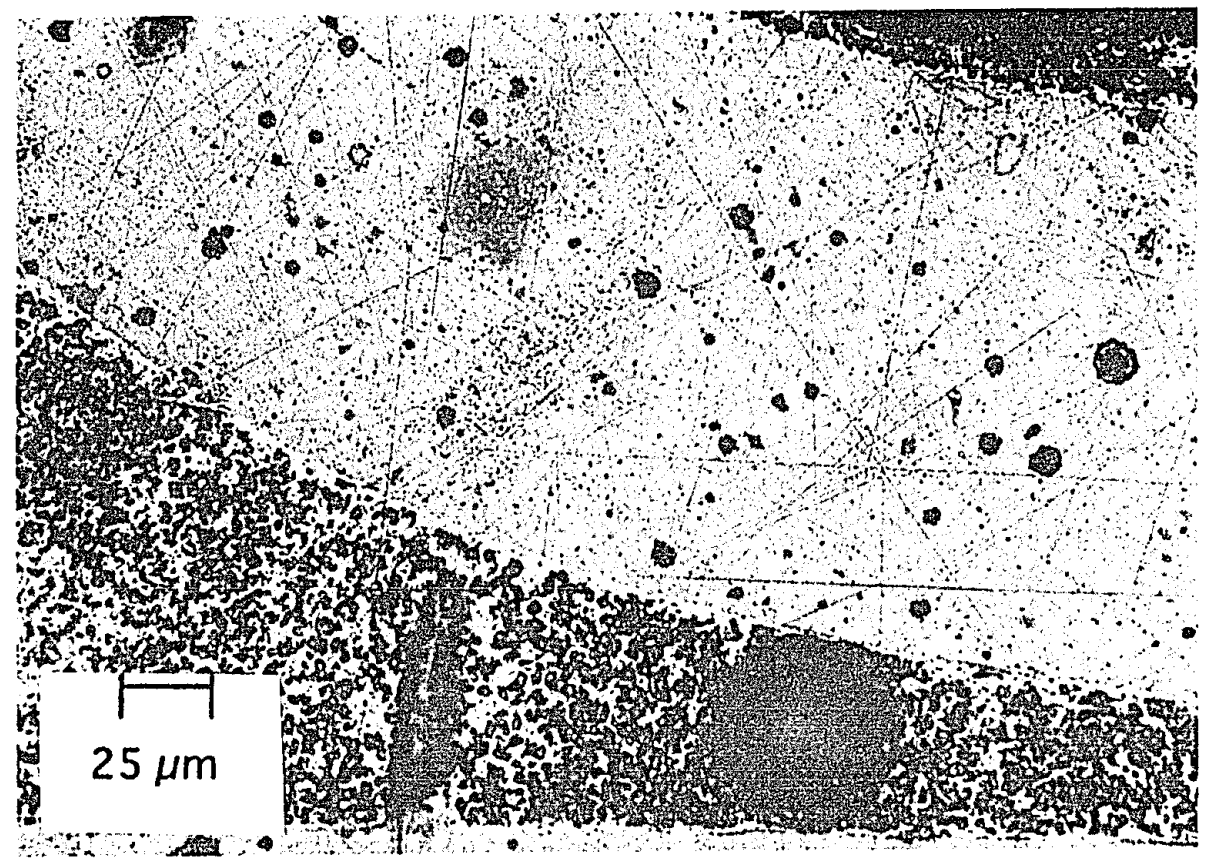

Figure 17. A solder joint processed under the A.1 condition. The contrasting curved region between the copper lead and the gray solder fillet is the $\mathrm{Cu}_{6} \mathrm{Sn}_{5}$ and $\mathrm{Cu}_{3} \mathrm{Sn}$ intermetallic layer. This photomicrograph is at $400 \mathrm{X}$ magnification. 


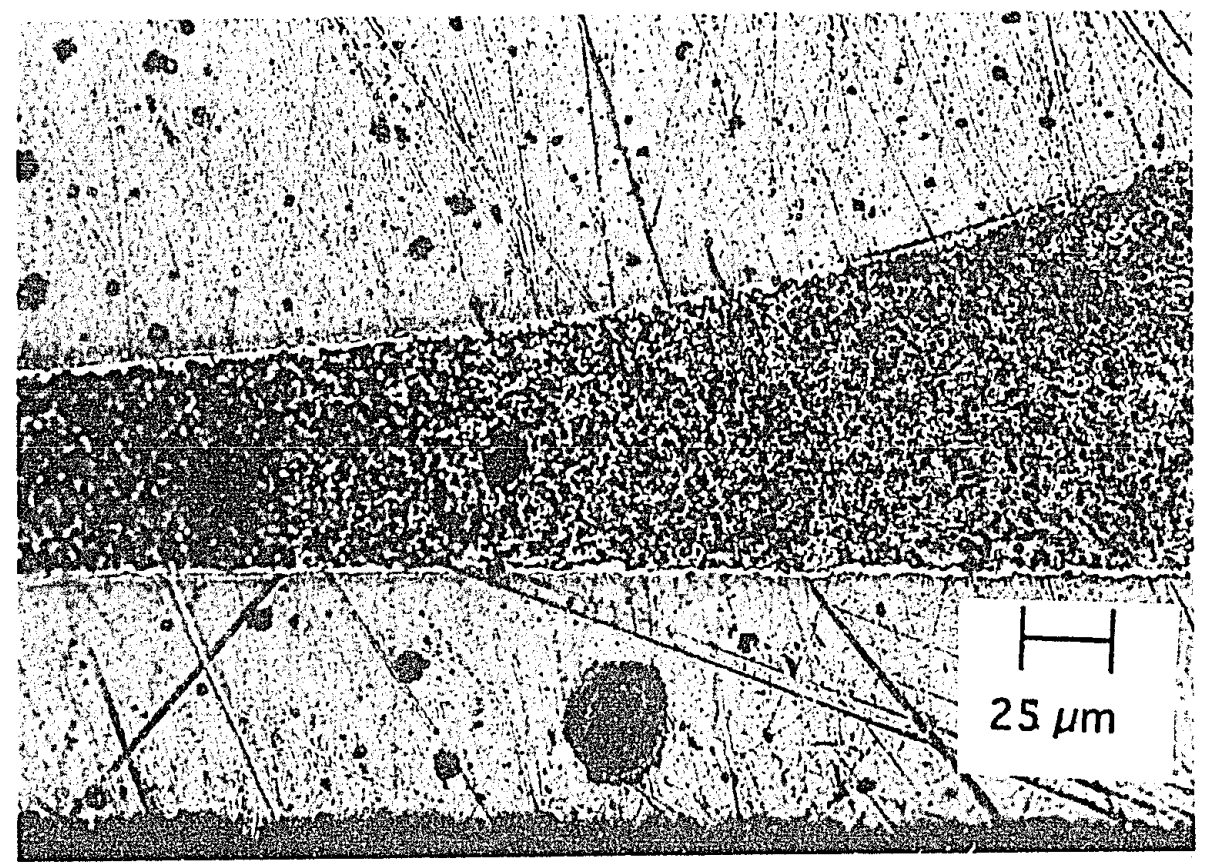

Figure 18. A micrograph of a solder joint in an A.2 assembly. The magnification is 400X. 


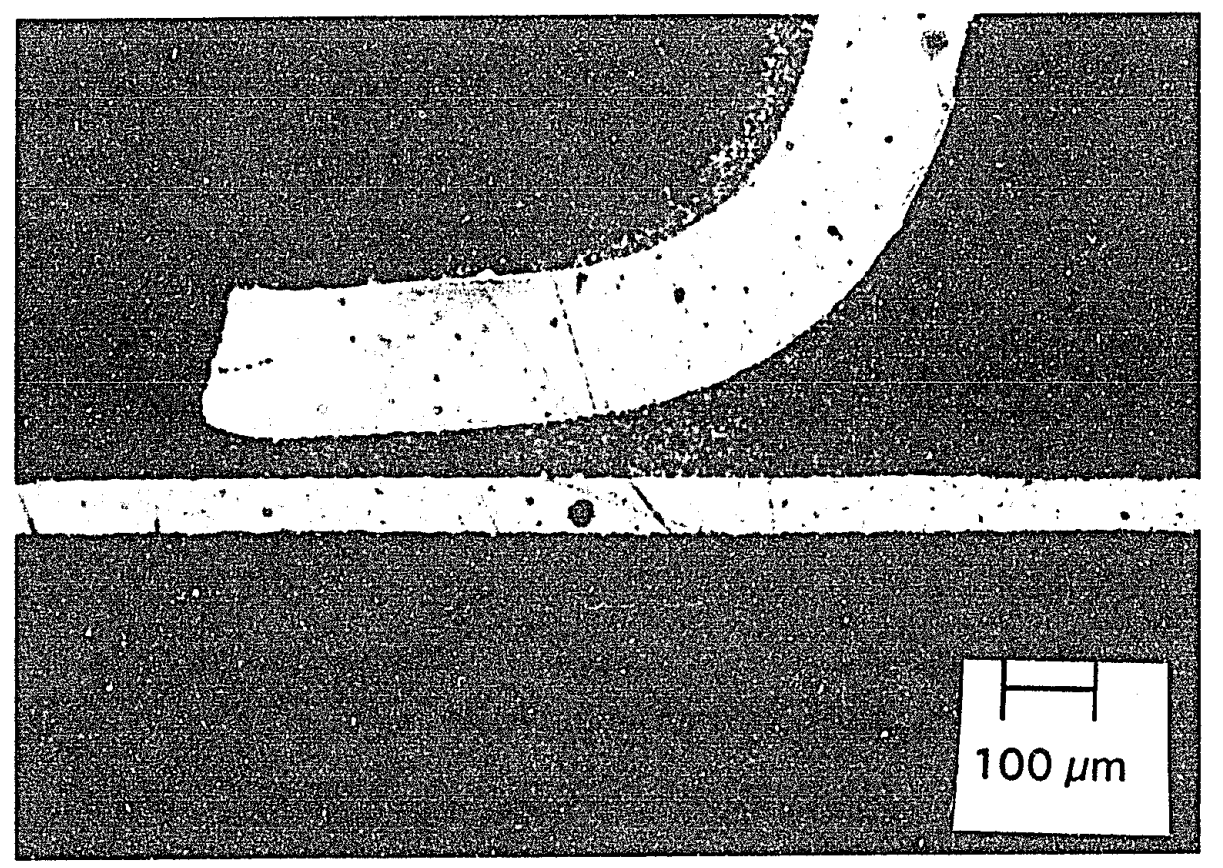

Figure 19. An overview of a typical solder joint in an A.1 assembly showing the uniformity of the intermetallic layer. This micrograph was taken at $100 \mathrm{X}$ magnification

\subsubsection{Solder Joint Defects in the $C$ and D Assemblies}

Voids were observed in the solder fillet of some joints in each of the assembly types inspected. There were two major locations where voids were found. One position was directly under the lead as shown in Figures 17 and 20 and the other location was at the fillet region adjacent to the lead as shown in Figure 21. 


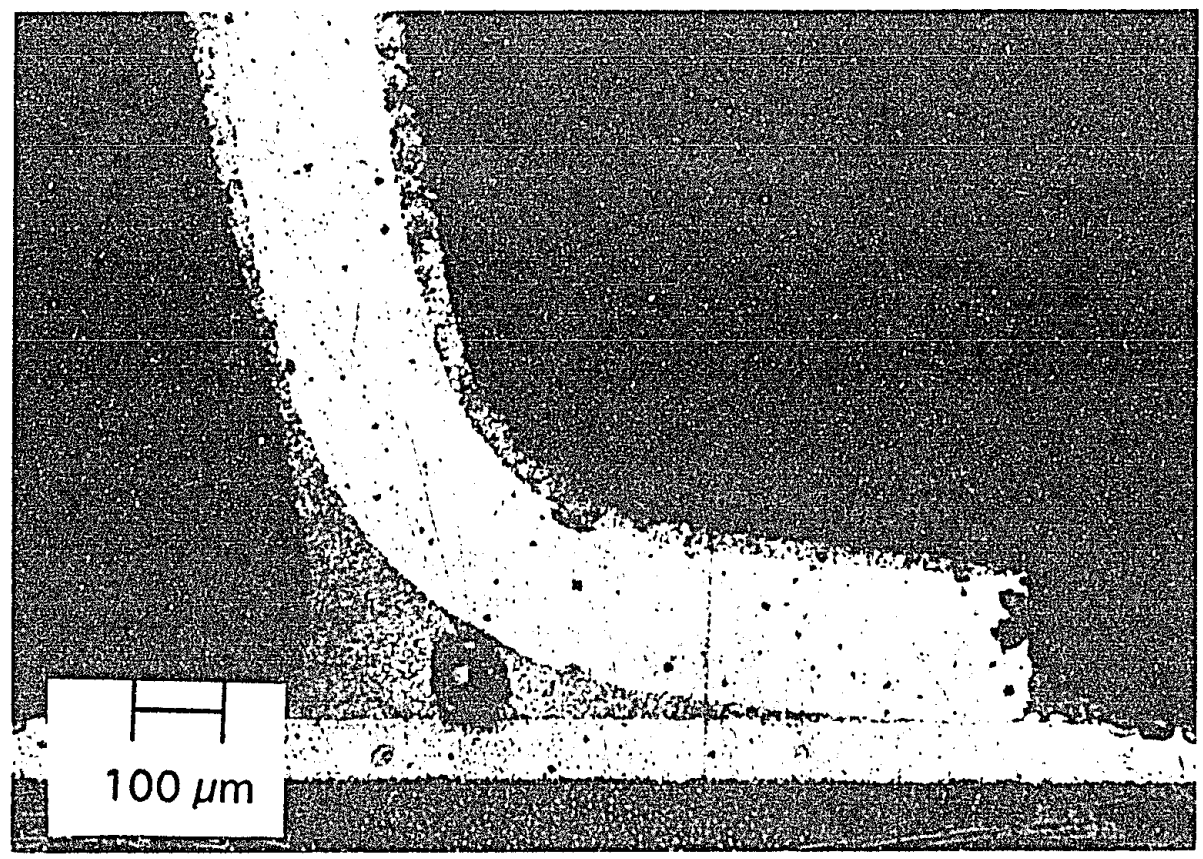

Figure 20. A gull-wing lead showing the presence of a void extending from the soldering land to the lead. This is an A.1 assembly magnified 100X.

An integrated count of voids during sequential sectioning from the frontal polished copper leadframe specimens was performed for the $C$ and $D$ assemblies. The concentration of voids per lead and a projected areal density of the footprint of the fillet area for is given in Tables 7 and 8. A trend can be seen from this information. In both cases, a significantly greater number of voids occurred on the fillets with leads on sides I and II of the packages (as defined in Figure 9). The side III fillets trail slightly behind in void density. The side IV fillets were found to contain very few voids. 


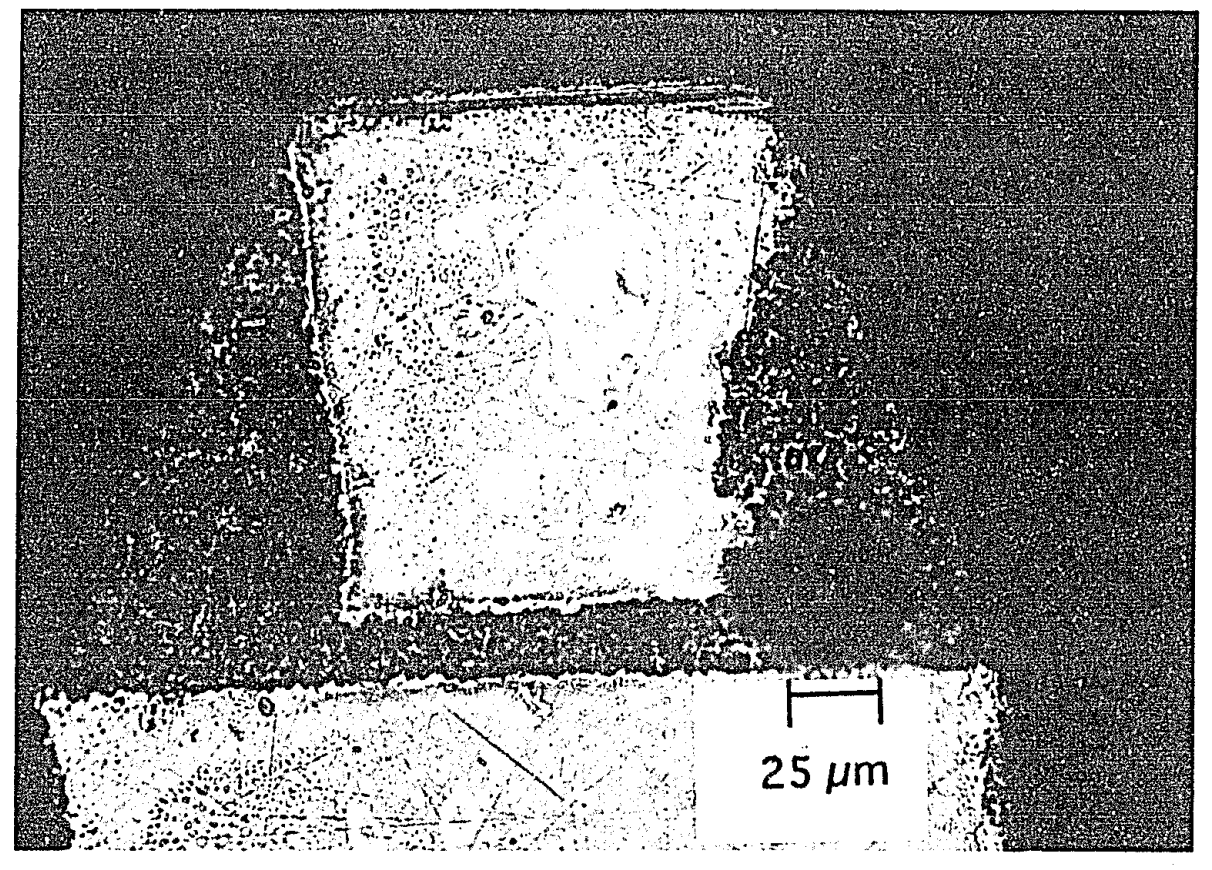

Figure 21. A frontal polished $C$ assembly with a void in the fillet in a region adjacent to the edge of the lead. This view is magnified 400X.

Table 7. Void Density in the Type C Assemblies

\begin{tabular}{lll}
\hline Side of Package & \#Voids/ \#Leads & $\begin{array}{l}\text { \#Voids/ Fillet Area } \\
\text { (\#voids/ sq. mm) }\end{array}$ \\
\hline TI & 0.13 & 1.70 \\
III & 0.17 & 2.19 \\
IV & 0.12 & 1.46 \\
\hline
\end{tabular}

Table 8. Void Density in the Type D Assemblies

\begin{tabular}{lll}
\hline Side of Package & \#Voids/ \#Leads & $\begin{array}{l}\text { \#Voids/ Fillet Area } \\
\text { (\#voids/ sq. mm) }\end{array}$ \\
\hline II & 0.21 & 2.68 \\
III & 0.15 & 1.95 \\
IV & 0.13 & 1.70 \\
\hline
\end{tabular}




\subsection{Fatigue Failure of Package Leads}

Joint breakage with lead separation was not observed with any quantifiable regularity with the Types $A$ series, $C$ or $D$ assemblies, respectively, under the vibration conditions as shown in Table 4. However, approximately one half of the leads of the $B$ assemblies failed in the fashion where cracks initiate in the heel and propagate along the intermetallic/fillet interface towards the toe (section 6.3). The B assemblies were subjected to a far greater number of loading cycles than the other assemblies (approximately 9 million cycles at a low acceleration). The total accumulated number of cycles for the Type B assemblies is 7 times greater than that for the A series assemblies, 11 times greater than that for the $C$ assemblies, and 5 times greater than that of the $D$ assemblies, respectively. In the author's and advisor's opinion, had funding and logistical problems not interfered with Type A.1 and A.2 assembly production and testing, quantitative integrity data could have been obtained for these specially designed test vehicles.

The Type $C$ assemblies, which were subjected to large accelerations and a relatively low number of cycles displayed assembly failure in the lead rather than at the solder joint. The lead failure occurred at the shoulders. The Alloy 42 leads displayed lower fatigue resistance than the copper alloy leads. Nearly all 208 leads except for one or two per package side were completely broken directly after the vibration testing. Figure 22 is a photomicrograph displaying an Alloy 42 lead with a fractured shoulder.

The copper alloy leads did not show visible shoulder damage after equivalent test conditions. However, much fatigue damage was accumulated as 
some of the leads did not survive the minor sustained load imposed by the low speed metallography saw during the sectioning procedure. The upper portion of the package separated from the leads at the shoulders along two package sides (II and III, respectively) These sides are those with closer proximity to the fixture point on the vibration unit. Figure 23 is an orthogonal view of broken copper alloy lead shoulders.

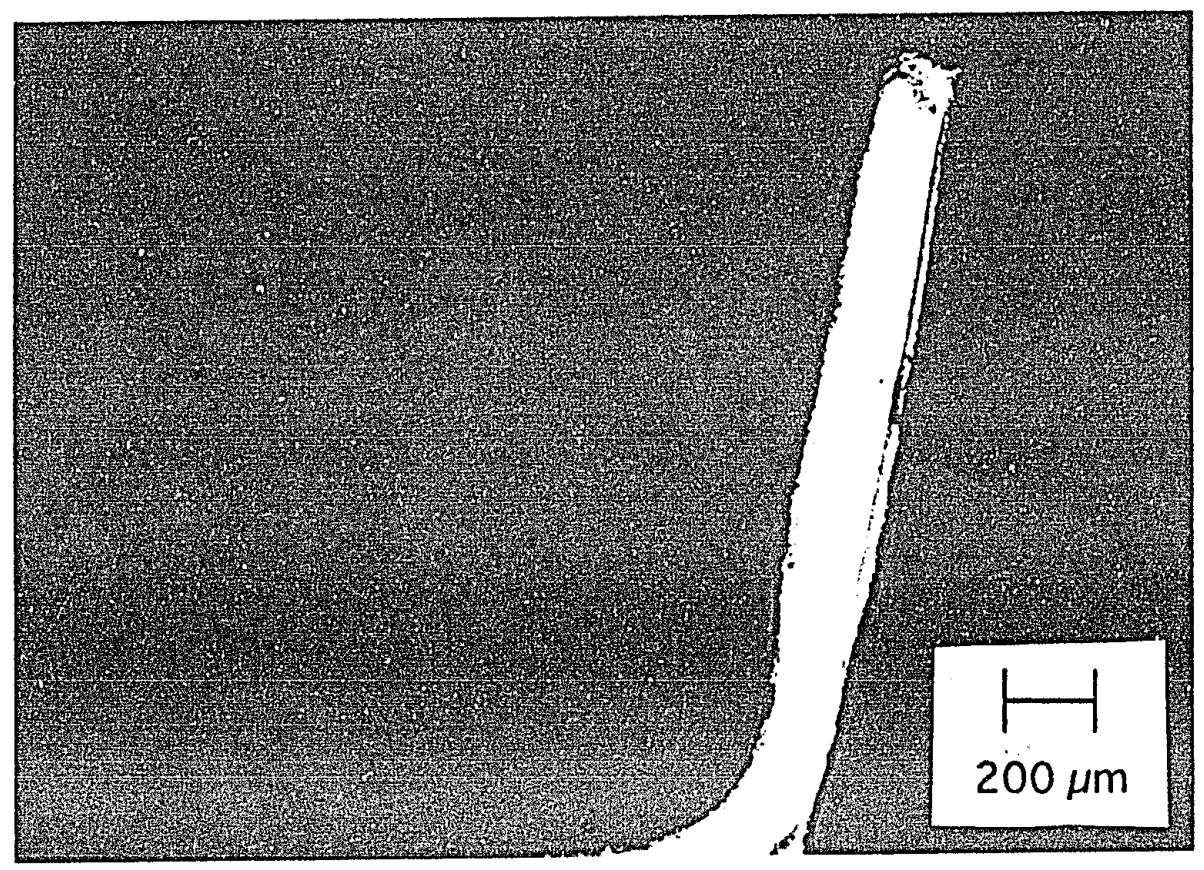

Figure 22. A profile view of an Alloy 42 lead broken at the shoulder. The magnification is 50X. 


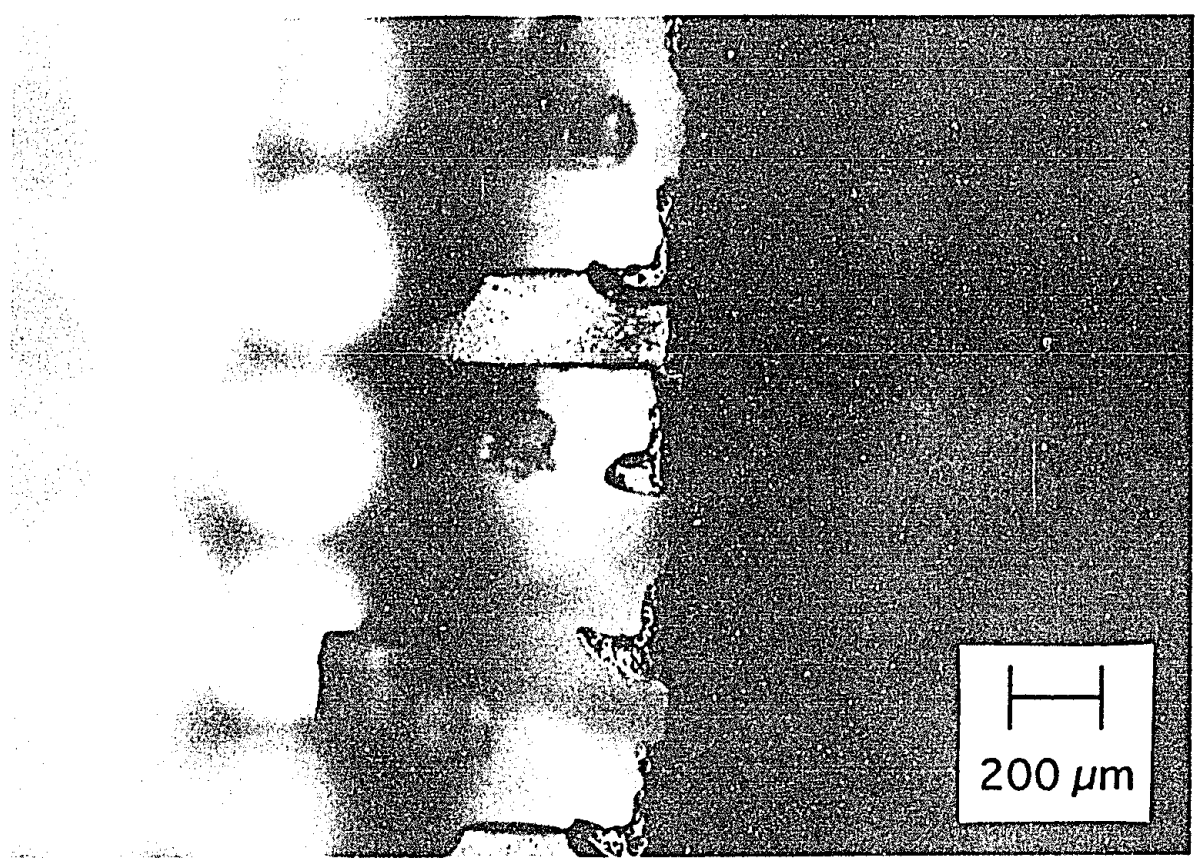

Figure 23. A top view of the fractured shoulders of a copper alloy 208 lead MQFP. The magnification is $50 \mathrm{X}$ 
One feature of the broken leads is the presence of multiple crack origins in the solder plating on the inner bend of the shoulder turn near the fracture surface. Cracks were also present at the intermetallic layer. This latter observation is depicted in the photomicrograph of Figure 24.

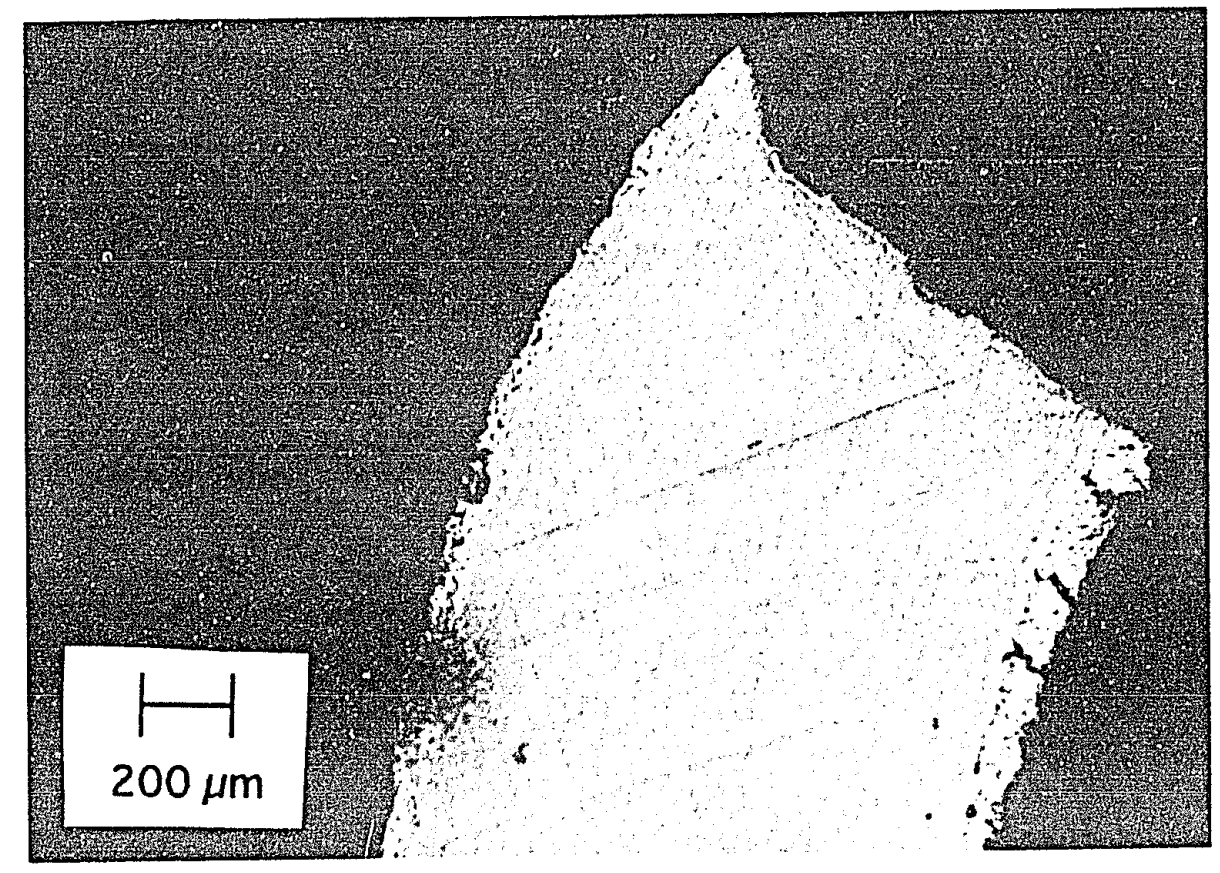

Figure 24. A close-up view of a copper lead at the fracture origin. Note the multiple crack origins in the solder plating. The magnification is $400 \mathrm{X}$. 
6.3 Examination of the Solder Joint Fracture and Determination of Fracture Mechanism

Cracked solder joints from the A.1, A.2, and B assemblies provided evidence to elucidate the fracture mechanism of fine pitch joints due to highcycle, low-amplitude fatigue excitation. Figure 25 shows the very beginning of a tiny crack emanating from the near the center of the heel of a Type A.1 assembly. The crack travels parallel to the plane of the printed circuit board until it intercepts the intermetallic layer/solder interface and then changes direction and propagates along that interface. The observation that the crack is continuous from the heel but not the toe indicates that the crack nucleated at the heel and propagated forward through the foot.

Figure 26 is an optical micrograph of a Type B assembly showing the profile of a crack that progressed further along the interface. The solder joint in Figure 27 is representative of a completely separated Type A.1 assembly lead. Note the crack following the intermetallic layer/fillet interface even at the front end of the lead. Figure 28 is a scanning electron micrograph which reveals the presence of intermetallics at the fracture surface and confirms crack propagation along this interface. The scanning electron micrograph in Figure 29 is of a fractured specimen showing a characteristic plateau region at the heel where cracking originates. 


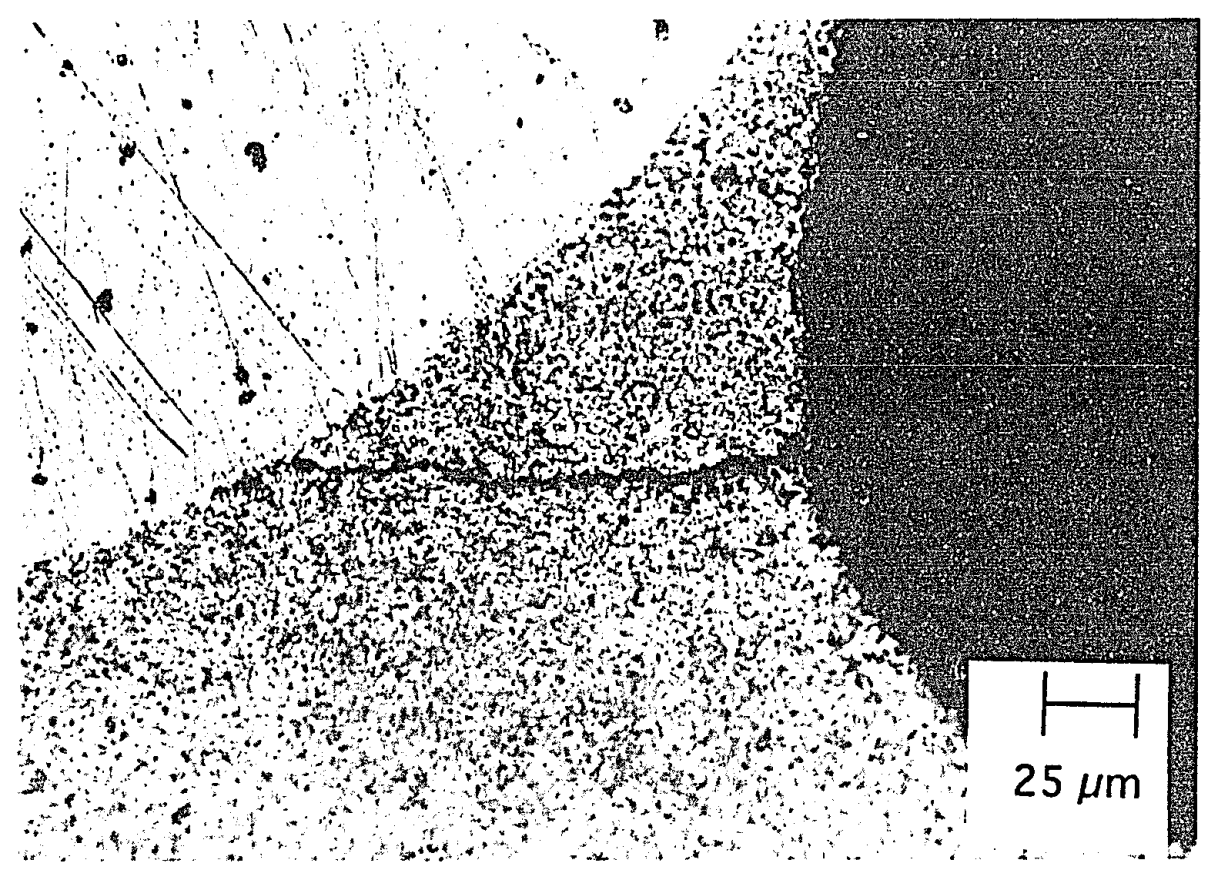

Figure 25. Crack initiation at the fillet heel. Note the genesis of crack progression along the intermetallic layer/fillet interface. This micrograph is of a 208 lead $0.5 \mathrm{~mm}$ pitch MQFP. The magnification is $400 \mathrm{X}$. 


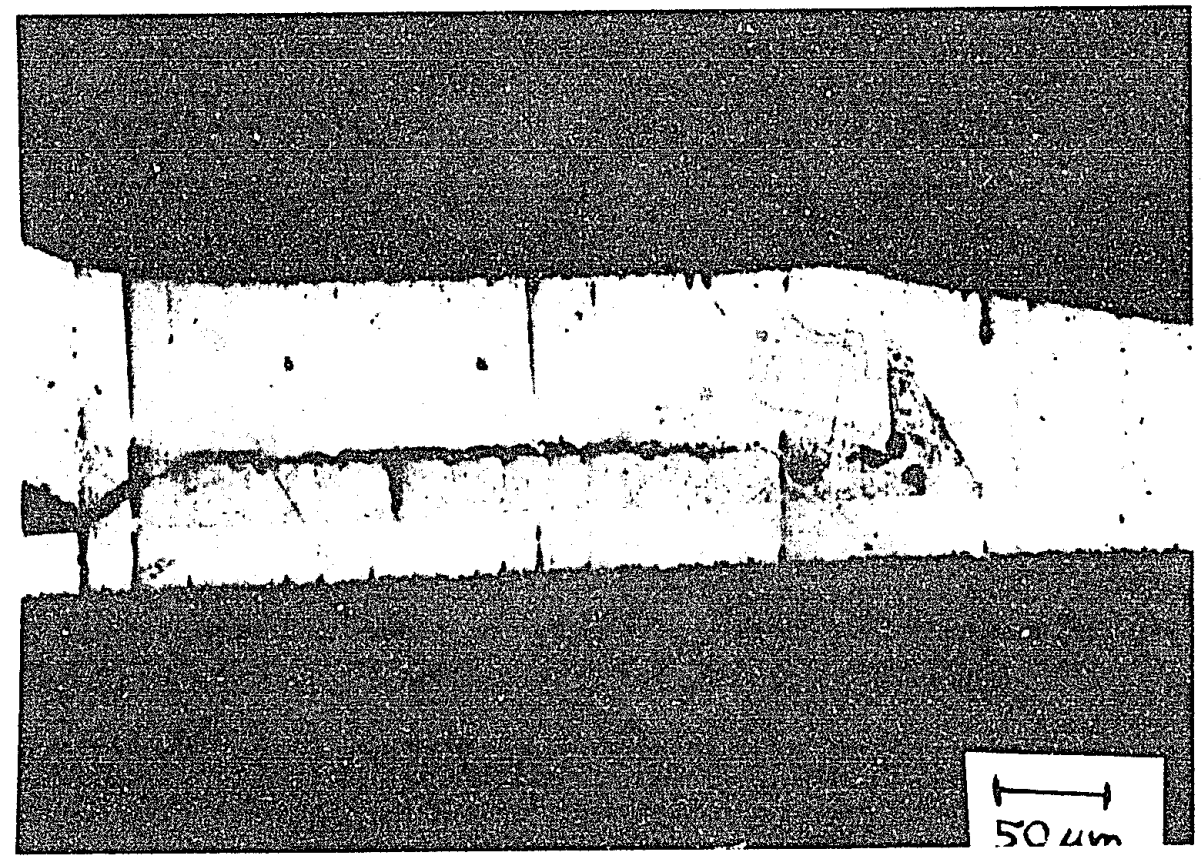

Figure 26. A cross sectional view of a polished partially cracked lead. This optical micrograph was taken at a magnification of $200 \mathrm{X}$. 


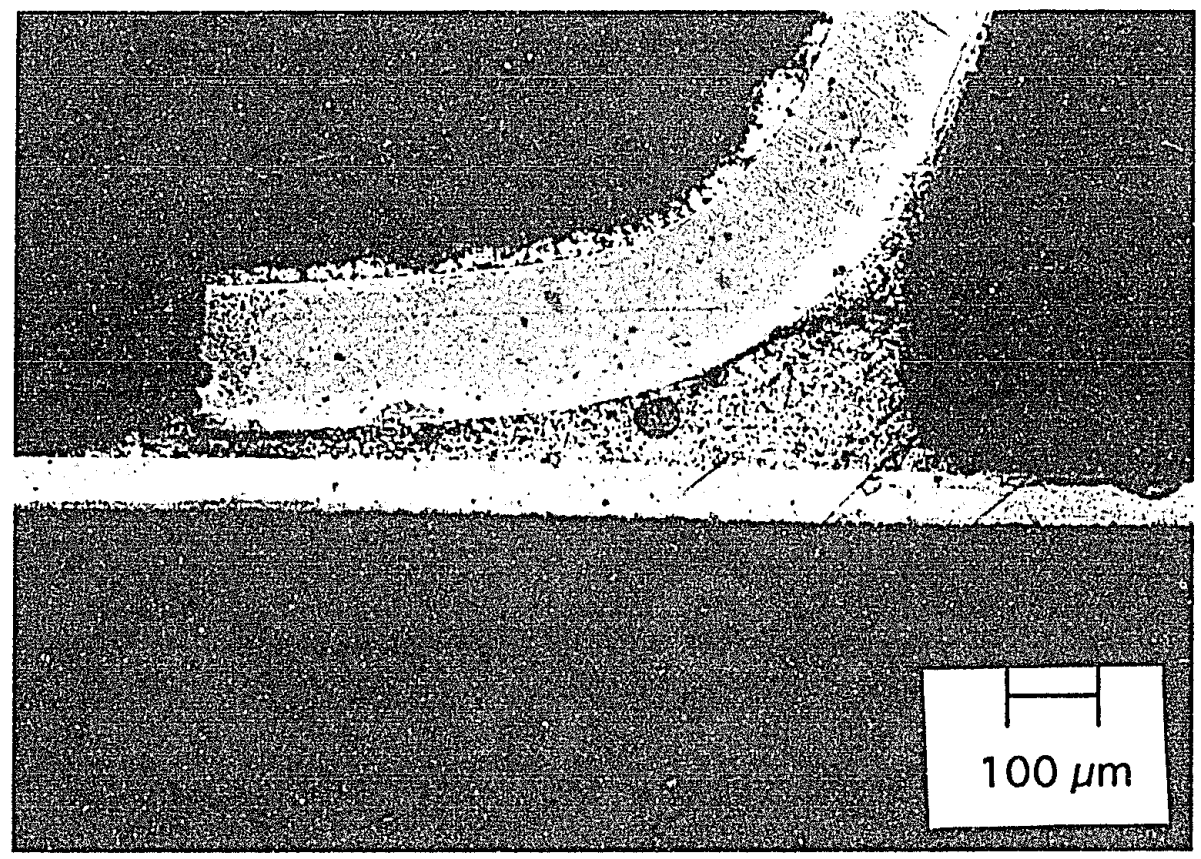

Figure 27. Cross section of a lifted lead. The package shown here is a 160 lead $0.65 \mathrm{~mm}$ pitch MQFP. The magnification is $100 \mathrm{X}$. 


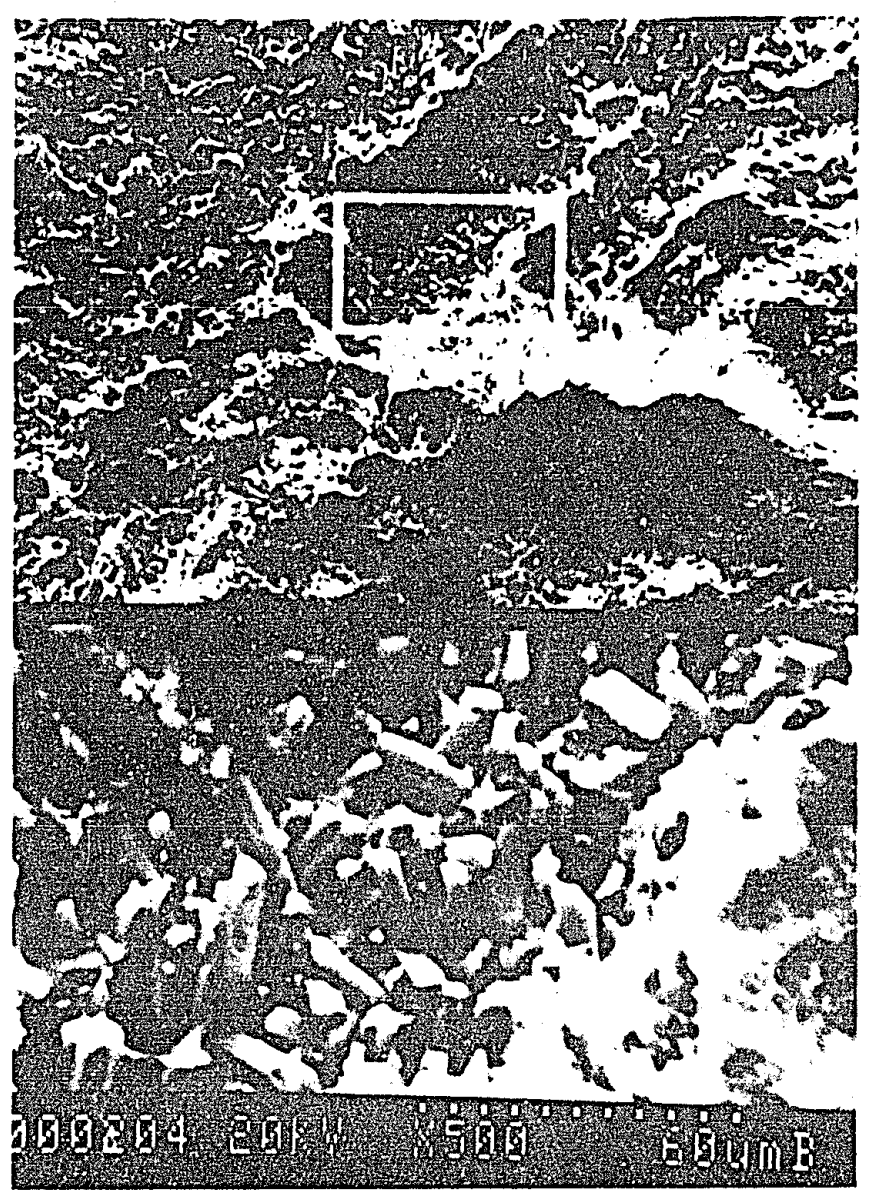

Figure 28. SEM micrograph of the fracture surface showing the presence of intermetallics along the lead/solder interface. The lower portion of the Figure is an enlarged view of the cropped region in the upper portion. 


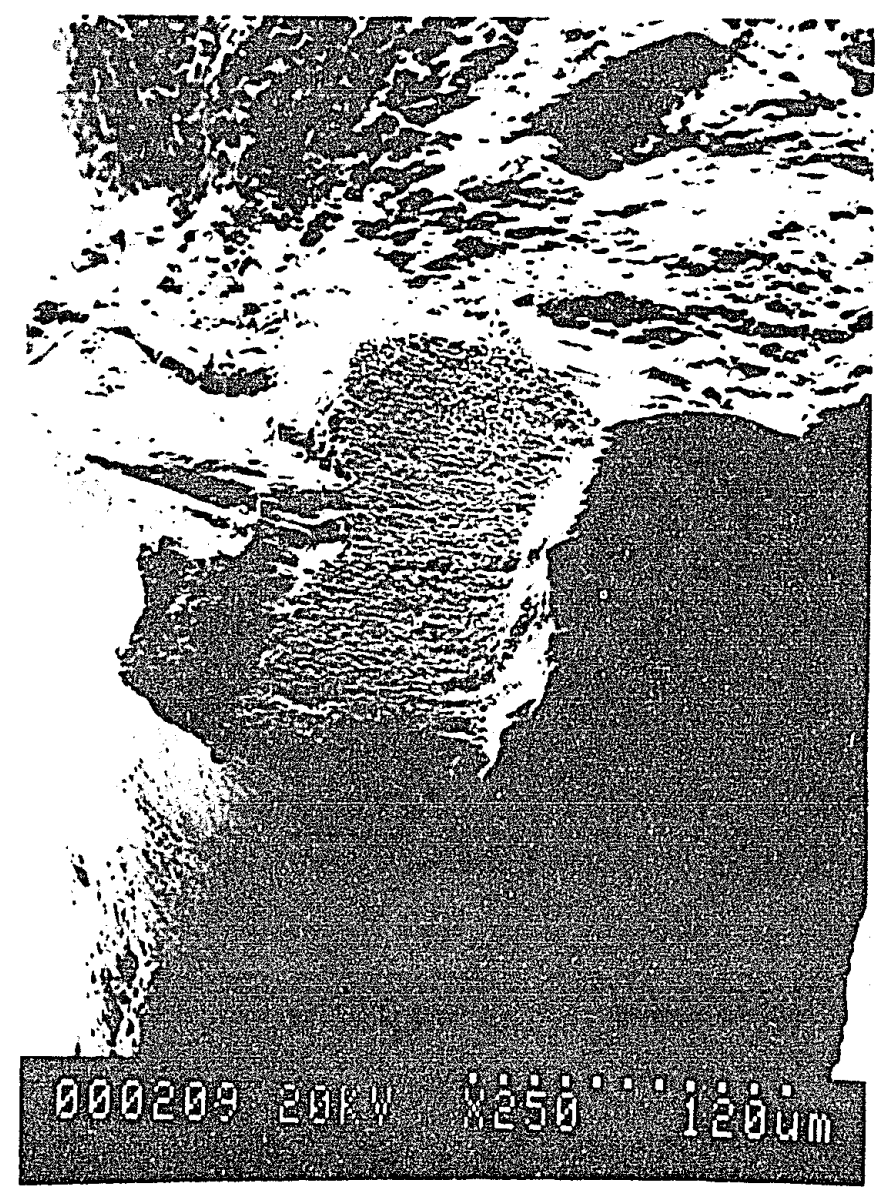

Figure 29. A scanning electron micrograph showing a plateau at the heel of the fillet where cracks initiate. This micrograph is magnified $250 \mathrm{X}$. 


\section{DISCUSSION}

\subsection{Process Control}

\subsubsection{Intermetallic Formation}

The lack of a measurable difference in the intermetallic layer between the A.1 assemblies and the A.2 assemblies illustrates that a large variation in thermal profile of a commercial IR reflow oven of conventional design (such as the Vitronics SMD 722) does not result in observable differences in intermetallic formation. In fact, commercial reflow systems are control-limited to minimize this possibility. In the experimental attempt to kinetically enhance intermetallic formation during the reflow operation of the Type A.2 assemblies, the Vitronics SMD 722 automatically drops power to the infrared emitters at a peak temperature of approximately $230^{\circ} \mathrm{C}$. This peak temperature is what is required to process the Type A.1 (typical condition) assemblies and is a typical set for commercial production. Thus, standard IR reflow profiles are being operated at the maximum temperatures the ovens will allow.

The Type A.1 assemblies were subjected to a dwell time above the eutectic temperature of 60 seconds as can been seen from Figure 16. The corresponding time for the Type A.2 assemblies is 110 seconds. The lack of intermetallic thickness difference observed between the Types A.1 and A.2 assemblies, respectively, can be explained by the diffusion penetration distance equation which states

$$
x=\sqrt{D t}
$$

where $x$ is the distance over which atoms are redistributed over the course of time $t . D$ is the diffusion coefficient of tin in copper and is effectively a constant 
for both reflow processes as the peak temperatures experienced by both types of assemblies are nearly identical. The calculated ratio of diffusion distance of the A.2 assemblies to the A.1 assemblies is 1.3. Utilizing the value of $4 \mu \mathrm{m}$ for the intermetallic thickness of the A.1 assemblies, the thickness of the layer of the A.2 assemblies would result in a value of $5.2 \mu \mathrm{m}$. This result is within the measurement limit of $\pm 1.5 \mu \mathrm{m}$ of the optical method employed.

In order to obtain metallurgical data on the intermetallic formation in gullwing leads, more extreme parameters (such as larger differences in dwell times and profile dynamics are necessary). Such requirements are not practically obtainable with production equipment and within the logistics of a working manufacturing environment. Laboratory ovens and standard aging treatments need to be employed.

\subsubsection{Void Formation}

The time-temperature profiles revealed a center to edge change of peak temperature of approximately $20^{\circ} \mathrm{C}$ as shown in the time-temperature plots of the Type A.1 assemblies in Figure 14. An inaccuracy exists in standard timetemperature profiling due to the fact that the thermocouples actually rest on the FR-4 board and are not in direct thermal contact with the lead. It is very difficult to attach a thermocouple directly to a lead in a moving conveyor without disturbing the alignment of the component to the printed circuit board, especially with fine pitch packages. However, if a dedicated experiment was to be performed, one designed to obtain specifically lead temperature on an assembly line reflow operation, it would require a special test assembly and use of a high temperature solder. 
A consequence of the non-uniform heat distribution along a package edge is the formation of voids within the fillet. Inspection of the $C$ and $D$ assemblies showed a greater incidence of voiding on the two sides of the copper lead package that were closer to the board center. Since it has been determined that actual temperatures in a given assembly during IR reflow varies with organic mass and that temperature are generally higher towards the center of the board, it is reasonable to conclude that voids are statistically more probable to form where solder paste reflow temperatures are higher. Additionally, from inspection of Figure 14, it can be seen that the center temperature profile is generally less dynamic and ramp rates are lower both upon heating and cooling than those of the edge temperatures. These characteristics appear to combine in poorer thermodynamic and kinetic conditions for the outgassing of the non-metallic materials during the soldering process.

There are consistent characteristics to the two types of voids formed. Voids formed underneath the lead always have a diameter equal to the distance from the soldering land on the board to the bottom surface of the lead. Thus, the size of the void is a function of the distance of formation along the centerline of the gull-wing lead and growth within the fillet is limited by the physical barrier of fillet thickness. However, the voids found in the fillet region adjacent to the lead had outer perimeters which did not extend to the outer surface of the fillet. The voids were encased within the solder. This phenomenon is due to the fact that energy to grow the void did not exceed the surface tension of the liquefied solder during the reflow process. If the boundary of this type of void extended beyond the fillet, it would have outgassed from the molten solder during the reflow process. 


\subsection{X-ray Laminography as an Analytical Tool}

The data provided by the $4 \Pi X$-ray Laminography system is not suitable for detailed analytical work. Its main design feature is scanning speed, not detailed information or a solder joint integrity evaluation. The fillet geometry provided by the machine's output can allow for the engineer some interpretation as to whether a given process is deviating from a nominal value but cannot produce any quantifiable definition of quality. Specific defects such as cracks and voids are not necessarily detected. Direct correlation of data between the X-ray laminography system and metallographic results was not performed. The geometric standard deviation reported by the instrument in the heel of the Type A.1 assemblies was $8 \mu \mathrm{m}$. Specific geometric data for the Type A.2 assemblies is possible but lies outside the scope of this project.

\subsection{Vibration Testing of Fine Pitch Solder Joints}

\subsubsection{Solder Joint Cracking}

It was observed that cracks nucleated at the center of the heel and propagated towards the intermetallic layer/fillet interface. Upon reaching this interface, the crack propagates forward towards the foot. There is such a great propensity for crack growth at this interface that when the crack reaches the front of the lead, the strain drives it to divert $90^{\circ}$ and travel up the front of the lead rather than forward out into the solder. This mechanism is shown in Figures 25 to 28.

The observed crack initiation and propagation mechanism concur with that proposed by Nakaoka, et al. ${ }^{(20)}$ It was found that, with a study of Alloy 42 gull-wing assemblies and peel testing, initiation occurred at the back heel of the 
fillet and subsequent growth takes place along the intermetallic/fillet interface. In addition, results of a 3-D finite element analysis performed by Lau, et al. ${ }^{(21)}$ are consistent with this mechanism.

Once cracks initiate and run through the solder to the intermetallic layer/fillet interface, they exclusively propagate along this interface. Thus, the volume of intermetallics at this layer does not play a role in the fatigue life during crack propagation of gull-wing solder joints. Their presence, not the volume fraction, is what governs their influence. Thus, one can argue that crack propagation, under out-of-plane fatigue loading, is not a strong function of the reflow process parameters.

Although it is rationalized that surface mount reflow conditions do not influence crack propagation, they may play a role in crack initiation. For example, the volume of intermetallic formation affects wetting properties of the solder.(22) This fact may produce poor fillet formation at the heel during reflow and create a greater inclination for crack initiation at the heel. Additionally, the eutectic colony size for $63 \mathrm{Sn} / 37 \mathrm{~Pb}$ solder is inversely proportional to the rate of cooling during the cool down stage of the reflow process. The fatigue resistance is inversely proportional to colony size. Thus, crack initiation may be strongly dependent on reflow conditions.

A plateau region was observed at the crack initiation region in the heel of the fillet as can be seen from Figure 29. This suggests an initial linear crack growth direction and a subsequent change of crack path. This observed behavior suggests that at a point of crack propagation within the heel, the principal strain path is in the forward direction and a change in crack path results. 


\subsubsection{Assembly Failure}

The solder joints that were subjected to out-of-plane vibration testing under three of the conditions imposed did not fail with any regularity at the solder joints. Solder joint failure was achieved only with a low accelerating force and a large number of cycles, which was applied to the Type B assemblies using an electromagnetic shaker table (refer to Table 4). This condition was a procedure which failed two entire sides of leads to the degree of visibility to the naked eye.

However, it was observed that at large acceleration vibrations, as imposed on the Type $C$ assemblies, failure of the assemblies occurred at the lead shoulders as is shown in Figures 22 to 24 . The location of failure is the first lead bend exiting the package body and failure occurred with a low number of loading cycles. Large accelerations subjected the leads to greater stresses per unit cycle and strained the less ductile lead materials such as the copper alloy and Alloy 42 to a greater degree than the more ductile $\mathrm{Pb}-\mathrm{Sn}$ eutectic solder in the joint. The property of elongation, a measure of ductility, is defined as:

$$
\text { ef }=\frac{L f-L_{0}}{L_{0}}
$$

where $e_{f}$ is the elongation, $L_{f}$ is the length at fracture, and $L_{o}$ is the gauge length. Listed in Table 9 are the elongation values for a typical copper alloy utilized in microelectronic packages and $\mathrm{Pb}-\mathrm{Sn}$ eutectic solder. The elongation of the eutectic solder is greater than ten times of that of the copper alloy. It should be noted that different gauge lengths are reported for the respective values. The value for the copper alloy was tested with a smaller gauge length. Tests conducted with identical gauge lengths should result in an even greater relative elongation of $\mathrm{Pb}-\mathrm{Sn}$ eutectic solder to copper. Ductile materials yield superior 
results for high strain fatigue conditions, whereas strong materials give the best results for low strain conditions.(24)

Table 9. Elongation for Copper and $\mathrm{Pb}-\mathrm{Sn}$ Eutectic Solder

\begin{tabular}{ll}
\hline Material & Elongation (\%) \\
\hline Copper C19400 (H08 Temper) & $3\left(L_{0}=50 \mathrm{~mm}\right)$ \\
Pb-Sn Eutectic Solder & $32\left(L_{0}=100 \mathrm{~mm}\right)$ \\
\hline
\end{tabular}

Source: Metals Handbook. Tenth Ed. Volume 2, ASM International, Materials Park, Ohio, (1990), pp. 291 and 522.

The failure of the leads at the shoulders present it as the point of highest stress concentration. The stress-concentration factor, $K_{t}$ is given by the relationship

$$
K t \propto \frac{1}{\sqrt{\rho}}
$$

where $\rho$ is the radius of curvature for a crack tip.

The 208 lead MQFP leads have two bends, one at the shoulders and one that forms the gull-wing configuration. At the inner side of the shoulder bend, multiple crack initiation was observed in the solder plating and propagated to the lead. The inner shoulder radius is $0.13 \mathrm{~mm}$. The gull-wing bend, on the other hand, has a radius of $0.30 \mathrm{~mm}$. The shoulder bend therefore has a higher stress concentration. In addition, the thin electroplated layer promotes initiation. The radius of curvature of the bend provides an "easy" means to nucleate the crack. This was confirmed by the multiple crack initiation depicted in Figure 24. It should be noted that the multiple cracking observed in the solder plating may have occurred during the forming of the gull-wing lead, as the electrodeposited solder is present during the bend-forming operation. 


\subsection{Out-of-Plane Vibration Testing and Process Evaluation}

\subsubsection{Vibration Testing as a Measure of Solder Joint Integrity .}

Vibration testing is not a method suitable for determining the volume of $\mathrm{Cu}_{6} \mathrm{Sn}_{5}$ and $\mathrm{Cu}_{3} \mathrm{Sn}$ intermetallic formation during the infrared reflow process. Crack propagation resulting from vibrations occurs along the intermetallic/ fillet interface and is independent of intermetallic volume. However, the variance in volume of $\mathrm{Cu}_{6} \mathrm{Sn}_{5}$ and $\mathrm{Cu}_{3} \mathrm{Sn}$ intermetallic formed within the parameters of a commercial reflow process window is not significant and not a factor for IR reflow process verification.

The sensitivity of vibration testing to the presence of voids in the solder fillet has not been determined. Voids were observed in the A.1 and A.2 specimens during destructive examination but due to the malfunctioning of the data acquisition system, no results were obtained. The presence of voids may increase or decrease an assembly's number of cycles to failure. Voids formed underneath a lead extend to the leads intermetallic layer, thereby decreasing surface adhesion area and possibly producing a solder joint of lesser integrity. Additionally, both types of voids formed, those underneath the lead and those in a region of the fillet adjacent to a lead edge, may diminish the structural integrity of the solder joint. A finite element model can provide information on this factor.

On the other hand, the presence of voids underneath the lead may enhance fatigue resistance. Since cracks propagate along the intermetallic layer/ fillet interface and this type of void extends to the intermetallic layer, it is possible that the void may obstruct the progression of the crack. Crack nucleation would need to initiate once again at a point eisewhere than the heel. 


\subsubsection{Implementation of Vibration Testing}

Vibration testing was determined to be impractical as a process verification tool because of its unique requirements. Results indicated only the Type B assemblies (refer to Table 4 for test conditions) displayed any type of quantifiable solder joint failure. These assemblies were tested at low acceleration with approximately 10 million loading cycles. Obtaining solder joint failure requires a long test duration and is time intensive. Failure also requires a narrow set of test conditions with respect to frequency, amplitude and the mechanical coupling configuration of the assembly to the test equipment. This condition is unique to each test assembly design.

Interfacing electrically and mechanically with the data acquisition system requires a specifically designed test assembly. Attachment method of the assembly to the shaker unit is another factor that needs to be addressed in the design. A special test vehicle designed with specifications for compatibility with the testing system will need to be far more simple than commercial assemblies in many aspects including component quantity, component variation, and printed circuit board size variation. The test assemblies would not be indicative of realworld products. Results obtained with the testing when applied to commercial assemblies will necessitate a considerable degree of extrapolation and assumption.

In addition, an experimental matrix of process variation is necessary to validate a device intended for process verification. A great number of samples are required to obtain statistically meaningful results. This is both cost intensive and time intensive due to the long test duration required to even obtain one assembly with failure at the solder joints. 


\section{CONCLUSIONS}

This study investigated the aspect of the mechanical integrity of fine pitch surface mount technology assemblies. The following are the conclusions obtained from these experiments:

\subsection{Process Effects}

\subsubsection{Process Control in a Commercial Assembly Line}

Processing conditions for a fine pitch surface mount assembly within the parameters of a commercial infrared reflow oven do not yield a significant change in the volume of intermetallics formed in the solder joints. Voids were observed within the solder fillet of commercially processed assemblies. However, fillet geometry variation does occur as shown by the $X$-ray laminography technique.

\subsubsection{Thermal Differential Across an Assembly during Reflow}

The probability of voids in the solder fillet in a given package is greater at the areas closer to the center of the assembly where process temperatures are generally higher and less dynamic. This results in trapped gases released by the solder flux during the reflow process thereby producing voids. The center of a board typically is the area of greatest component density. Component placement with regard to bulk in the design of an assembly is necessary in order to minimize the likelihood of voids. 


\subsection{Qut-of-plane Vibration Testing}

\subsubsection{Crack Mechanism at a Gull-wing Solder Joint}

Cracking for a gull-wing joint initiates at the heel. The crack then traversed through the solder to the interface between the intermetallic layer and the solder fillet. It is on this interface where all subsequent propagation occurs. Cracking is dependent on the presence of this interface and not on intermetallic volume since the crack does not propagate through the intermetallic layer.

\subsubsection{The Character of Lead Failure}

Vibration testing with a low accelerating force to produce failure in a gullwing joint requires a large number of loading cycles. Joint failure without shoulder failure was not observed until the specimens were subjected to approximately 10 million loading cycles.

Failure of the assembly when subjected to large accelerations and low cycle fatigue was found in the copper and Alloy 42 leads. The more ductile $\mathrm{Pb}-\mathrm{Sn}$ eutectic solder at the joint did not fail under these testing conditions.

Failure in the leads occurred at the lead shoulders rather than at the joint region. This result is due to the fact that the inner side of the shoulder bend is the highest point of stress concentration containing the smallest radius of curvature in the lead design. The property of ductility determined the material that fractured. The cracks occurred within the leads consisting of copper or Alloy 42 and not in the more ductile $\mathrm{Pb}-\mathrm{Sn}$ eutectic solder fillet.

\subsubsection{Vibration Testing as a Process Verification Tool}

Crack propagation due to vibration testing is not dependent on intermetallic volume in the solder joint but on the presence of the intermetallic/ 
fillet interface. On the other hand, intermetallic volume affects wetting characteristics of the solder during the reflow process. This property defines the processed geometry of the fillet heel. Improperly formed heels may produce greater stress concentrations and may present a greater incidence of crack initiation.

However, utilizing vibration testing as a process verification tool requires a large number of loading cycles to produce joint failure. In addition, a large sample size of assemblies would be required for a small experimental matrix in order to obtain statistically meaningful data. The method is cost and time intensive to implement as a process verification tool. Furthermore, in order for an assembly to mechanically and electrical!y interface with the data acquisition system, uniquely designed test assemblies need to be employed. Thus, it would be only (at best) an indirect measure of solder joint integrity when its results are applied to a commercial product. 


\section{REFERENCES}

1) Prasad, R.P.,Surface Mount Technology-Principles and Practice Van Nostrand Reinhold, New York, (1989), pp. 10-18.

2) Hutchins, C.L.,"Technical Considerations in Vapor and Infrared Solder reflow Processes", Solder Joint Reliability-Theory and Applications, Lau, J.H., ed. Van Nostrand Reinhold, New York, (1991), p. 93.

3) Hutchins, C.L., "Optimization of Vapor Phase and Infrared Solder Reflow Processes", Proceedings of the Technical Program of the National Electronic Packaging and Production Conference-Nepcon West '87, vol. 1., Anaheim, CA, February 1987, Cahners Exposition Group, (1987), pp. 516-524.

4) Hutchins, C.L.,"Technical Considerations in Vapor and Infrared Solder reflow Processes", Solder Joint Reliability-Theory and Applications, Lau, J.H., ed. Van Nostrand Reinhold, New York, (1991), pp 95-98.

5) Prasad, R.P., ibid., pp. 106-107.

6) Groover, R., Bardel, G., and Sharan, A., "Assembly Considerations in Leadframe Design for High-Lead-Count MQFP Packages", The Technical Proceedings of SMTCON West ${ }_{2}$ San Diego, November 1991, IC Management Inc., (1991), p. 147.

7) Hoffer, K.O., "Solderability Testing of $\mathrm{Cu}_{6} \mathrm{Sn}_{5}$ Intermetallic", Proceedings of the Technical Program of the National Electronic Packaging and Production Conference-Nepcon West '91, Anaheim, Cahners Exposition Group, (1991), p. 994.

8) Johnson, C.C. and Kevra, J., Solder Paste Technology, TAB Professional and Reference Books, Blue Ridge Summit, PA, (1989), pp. 41-55.

9) Groover, R., Bardel, G., and Sharan, A., ibid., p. 148.

10) Devore, J.A., "The Makeup of a Surface-Mount Solder Joint", Circuits Manufacturing, vol. 13, no. 2, (1990), p. 42.

11) Prasad, R.P., ibid., pp. $453-454$.

12) Prasad, R.P., ibid., p. 104.

13) Prasad, R.P., ibid., pp. 485-487. 
14) Hwang, J.S., "Solder Paste Technology and Applications", Solder Joint Reliability-Theory and Applications, Lau J.H., ed., Van Nostrand Reinhold, New York, (1991), pp. 81-84

15) Preskitt, C.A., "Process Control and Defect Detection Using 3D X-ray

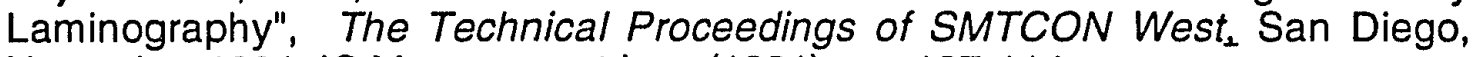
November 1991, IC Management Inc., (1991), pp. 107-114

16) Nakaoka, Y., Hirota, J., and Machida, K., "Mechanical Properties of Solder Joints in Surface Mounting", IEEE/CHMT '89 Japan IEMT Symposium, Proceedings, IEEE, (1989), pp.117-120.

17) Chen, W., "Analyzing the Mechanical Strength of SMT Attached Solder Joints", Seventh IEEE/CHMT '89 International Electronic Manufacturing Technology Symposium, Proceedings, San Francisco, September 1989, IEEE, (1989), pp.61-69.

18) Lau, J., Powers, L., Baker, J., Rice, D., and Shaw, B., "Solder Joint Reliability of Fine Pitch Surface Mount Technology Assemblies", Seventh IEEE/CHMT '89 International Electronic Manufacturing Technology Symposium, Proceedings, San Francisco, September 1989, IEEE, (1989) pp. 48-60.

19) Kazmierowicz, P. C., "Thermal Profiling Reflow Solder", Circuits Assembly, August 1992, Miller-Freeman Publications, San Francisco, (1992), pp. 59-62.

20) Lau, J.H., and Harkins, C.G., "Stiffness of PQFP 'Gull-Wing' Lead and Its Effect on Solder Joint Reliability", Fifth IEEE/CHMT International Electronic Manufacturing Technology Symposium-Design-to-Manufacture Transfer Cycle, Proceedings, Lake Buena Vista, FL., October 1988, IEEE, (1988), pp. 131-142.

21) Nakaoka, Y., Hirota, J., and Machida, K., ibid, pp.117-120.

22) Li, C., "The Correlation of Solder Joint Integrity to Wetting Properties of Electronic Component Leads", Master's Thesis, San Jose State University, (1988).

23) Mei, A., Morris, J. W., Shine, M. C., and Summers, T. S. E., "Effects of Cooling Rate on Mechanical Properties of Near-Eutectic Tin-Lead Solder Joints", Journal of Electronic Materials, Vol. 20, No. 8, (1991), pp 599-608.

24) Dieter, G.E., Mechanical Metallurgy, 3rd ed., McGraw-Hill, New York, (1986), pp. 500-501. 


\section{BIBLIOGRAPHY}

Devereux, O.F., Topics in Metallurgical Thermodynamics, Robert E. Krieger Publishing Company, Malabar, Florida, (1983).

Dieter, G.E., Mechanical Metallurgy, 3rd ed., McGraw-Hill, New York, (1986).

Dostel, C.A., Senior Ed., Electronic Materials Handbook, Volume 1, Packaging, ASM International, Materials Park, Ohio, (1989).

Eisberg, R. and Resnick, R, Quantum Physics of Atoms, Molecules, Solids, Nuclei, and Particles, 2nd ed., John Wiley and Sons, New York, (1985).

Hertzberg, R. W., Deformation and Fracture Mechanics of Engineering Materials 3rd Ed., Wiley, New York, (1989).

Johnson, C.C. and Kevra, J., Solder Paste Technology, TAB Professional and Reference Books, Blue Ridge Summit, PA, (1989).

Lau J.H., Ed., Solder Joint Reliability-Theory and Applications, Van Nostrand Reinhold, New York, (1991).

Prasad, R.P. Surface Mount Technology-Principles and Practice, Van Nostrand Reinhold, New York, (1989).

Tummala, R.R. and Rymaszewski E. J., Eds., Microelectronics Packaging Handbook, Van Nostrand Reinhold, New York, (1989). 